\title{
Characterization and Parametrization of Reynolds Stress and Turbulent Heat Flux in the Stably-Stratified Lower Arctic Troposphere Using Aircraft Measurements
}

\author{
Amir A. Aliabadi ${ }^{1}$ - Ralf M. Staebler ${ }^{2}$ - Michael Liu ${ }^{2}$. \\ Andreas Herber ${ }^{3}$
}

Received: 22 September 2015 / Accepted: 13 March 2016

(C) Her Majesty the Queen in Right of Canada 2016

\begin{abstract}
Aircraft measurements are used to characterize properties of clear-air turbulence in the lower Arctic troposphere. For typical vertical resolutions in general circulation models, there is evidence for both downgradient and countergradient vertical turbulent transport of momentum and heat in the mostly statically stable conditions within both the boundary layer and the free troposphere. Countergradient transport is enhanced in the free troposphere compared to the boundary layer. Three parametrizations are suggested to formulate the turbulent heat flux and are evaluated using the observations. The parametrization that accounts for the anisotropic nature of turbulence and buoyancy flux predicts both observed downgradient and countergradient transport of heat more accurately than those that do not. The inverse turbulent Prandtl number is found to only weakly decrease with increasing gradient Richardson number in a statistically significant way, but with large scatter in the data. The suggested parametrizations can potentially improve the performance of regional and global atmospheric models.
\end{abstract}

Keywords Arctic · Countergradient flux · Parametrization schemes · Planetary boundary layer $\cdot$ Subgrid-scale turbulence

\section{Introduction}

Parametrization of subgrid-scale (SGS) turbulence is an essential part of atmospheric modelling. Most operational regional and global atmospheric models parametrize SGS turbulence

Amir A. Aliabadi

aliabadi@aaa-scientists.com

1 Building Technology Program, Department of Architecture, Massachusetts Institute of Technology, Cambridge, USA

2 Air Quality Research Processes Section (AQRP), Air Quality Research Division (AQRD), Science and Technology Branch (STB), Environment and Climate Change Canada, Toronto, ON, Canada

3 The Alfred Wegener Institute, Helmholtz Centre for Polar and Marine Research, Bremerhaven, Germany 
by vertical diffusion of momentum, heat, moisture, and other atmospheric constituents above the surface layer (Cuxart et al. 2006). In this approach all relevant equations are simplified by Reynolds averaging, where each variable of interest is decomposed into a mean and a turbulent fluctuating part $\left(X=\bar{X}+X^{\prime}\right)$. A simplified set of boundary layer equations for continuity, momentum, and heat can be listed as (Stull 2003)

$$
\begin{aligned}
& \frac{\partial \overline{U_{j}}}{\partial x_{j}}=0, \\
& \frac{\partial \bar{U}}{\partial t}+\overline{U_{j}} \frac{\partial \bar{U}}{\partial x_{j}}=f\left(\bar{V}-\overline{V_{g}}\right)-\frac{\partial \overline{u^{\prime} u_{j}^{\prime}}}{\partial x_{j}}, \\
& \frac{\partial \bar{V}}{\partial t}+\overline{U_{j}} \frac{\partial \bar{V}}{\partial x_{j}}=f\left(\overline{U_{g}}-\bar{U}\right)-\frac{\partial \overline{v^{\prime} u_{j}^{\prime}}}{\partial x_{j}}, \\
& \frac{\partial \overline{\theta_{v}}}{\partial t}+\overline{U_{j}} \frac{\partial \overline{\theta_{v}}}{\partial x_{j}}=-\frac{1}{\bar{\rho} C_{p}}\left[L_{v} E+\frac{\partial \overline{Q_{j}^{*}}}{\partial x_{j}}+\right]-\frac{\partial \overline{\theta_{v}^{\prime} u_{j}^{\prime}}}{\partial x_{j}},
\end{aligned}
$$

where $\bar{U}$ and $\bar{V}$ are mean wind velocity components in the $x$ and $y$ directions (mean wind velocity in the $z$ direction $(\bar{W})$ is assumed zero), $f$ is the Coriolis parameter, subscript $g$ denotes geostrophic wind, $u^{\prime}, v^{\prime}$, and $w^{\prime}$ are turbulent wind velocity components in the $x, y$, and $z$ directions, $\overline{\theta_{v}}$ is the mean virtual potential temperature, $\bar{\rho}$ is the mean density, $C_{p}$ is the heat capacity of air at constant pressure, $L_{v}$ is the latent heat of vapourization of water, $E$ is the water vapour flux, $Q^{*}$ is the net radiation, and $\theta_{v}^{\prime}$ is the turbulent fluctuation in virtual potential temperature.

A fundamental difficulty with the above equations is the parametrization of the turbulent flux term $\left(\partial \overline{X^{\prime} u_{j}^{\prime}} / \partial x_{j}\right)$, particularly under statically stable conditions, where turbulence is intermittent and mixing is weak (Aliabadi et al. 2016a,b). Models that formulate turbulent fluxes as a function of other known variables fall under two major categories: models that only account for downgradient transport of momentum and heat, and models that account for both downgradient and countergradient transport of these quantities.

\subsection{Downgradient Transport}

In the case of one-dimensional vertical diffusion and assuming horizontal homogeneity (i.e. $\left.\frac{\partial}{\partial y}=\frac{\partial}{\partial x}=0\right)$, downgradient transport models assume that the Reynolds stress $\left(\overline{u^{\prime} w^{\prime}}\right)$ and turbulent heat flux $\left(\overline{\theta_{v}^{\prime} w^{\prime}}\right)$ (heat flux hereafter) are proportional to the vertical gradient of mean horizontal wind speed and virtual potential temperature

$$
\begin{aligned}
& \overline{u^{\prime} w^{\prime}}=-K_{m} \frac{\partial \bar{U}}{\partial z}, \\
& \overline{\theta_{v}^{\prime} w^{\prime}}=-K_{h} \frac{\partial \overline{\theta_{v}}}{\partial z},
\end{aligned}
$$

where horizontal wind speed is in the along-wind direction. Here we assume constancy of wind direction with height, so with the rotation of the coordinate frame along the $z$ axis we can obtain $\bar{V}=\frac{\partial \bar{V}}{\partial z}=0$ for notational convenience. This approximation is reasonable if short vertical distances are involved, which is the case in our analysis. $K_{m}$ and $K_{h}$ are the eddy viscosity (or momentum diffusivity) and eddy conductivity (or heat diffusivity), respectively. 
First-order models formulate diffusivity as a function of mixing length and stability [e.g. gradient Richardson number or Obukhov length, see Delage and Girard (1992), Delage (1997), Mahrt and Vickers (2003), Han et al. (2009)]. 1.5-order models formulate diffusivity as a function of turbulent kinetic energy $\left(e=\frac{1}{2}\left(\overline{u^{\prime 2}}+\overline{v^{\prime 2}}+\overline{w^{\prime 2}}\right)\right)$ and/or other variances of turbulent fluctuating components in addition to mixing length and stability (Mellor and Yamada 1974; Bougeault and Lacarrere 1989; Bélair et al. 1999; Cuxart et al. 2006). Full second- and third-order models may eliminate the need for momentum and heat diffusivity parametrization because they formulate and solve all second- and third-moment equations, respectively. However, their use is limited in operational models due to complexity and computational cost (Stull 2003).

The ratio of $K_{m}$ to $K_{h}$ quantifies the relative efficiency of momentum and heat transfer and is known as the turbulent Prandtl number,

$$
\operatorname{Pr}_{t}=\frac{\overline{u^{\prime} w^{\prime}} \frac{\partial \overline{\theta_{v}}}{\partial z}}{\overline{\theta_{v}^{\prime} w^{\prime}} \frac{\partial \bar{U}}{\partial z}}=\frac{K_{m}}{K_{h}},
$$

and if $P r_{t}$ is known, such a formulation allows for the determination of $K_{m}$ given $K_{h}$ or vice versa. $P r_{t}$ is usually formulated as a function of stability such as the gradient Richardson number,

$$
R i=\frac{g}{\overline{\theta_{v}}} \frac{\frac{\partial \overline{\theta_{v}}}{\partial z}}{\left(\frac{\partial \bar{U}}{\partial z}\right)^{2}},
$$

with $P r_{t} \approx 1$ under statically neutral or unstable conditions. It is, however, reported to increase with increasing gradient Richardson number in the statically stable regime (Kondo et al. 1978; Ueda et al. 1981; Kim and Mahrt 1992; Ohya 2001; Grachev et al. 2007a, b). This relationship is mostly verified on flux towers near the surface, for example the Surface Heat Budget of the Arctic (SHEBA) Ocean experiment with measurements under $20 \mathrm{~m}$ in height (Grachev et al. 2007a, b) or the 213-m flux tower covering the lower portion of the boundary layer used by Ueda et al. (1981). To the authors' knowledge, the only observational studies to verify this relationship at higher altitudes are the aircraft studies of Kennedy and Shapiro (1980) and Kim and Mahrt (1992), in which only a limited number of measurements were made.

\subsection{Downgradient and Countergradient Transport}

Models including the countergradient transport of momentum and heat introduce an additional term to the downgradient expression (Bélair et al. 1999),

$$
\begin{aligned}
& \overline{u^{\prime} w^{\prime}}=-K_{m}\left(\frac{\partial \bar{U}}{\partial z}-\Gamma_{m}\right), \\
& \overline{\theta_{v}^{\prime} w^{\prime}}=-K_{h}\left(\frac{\partial \overline{\theta_{v}}}{\partial z}-\Gamma_{h}\right),
\end{aligned}
$$

with $\Gamma_{m}$ and $\Gamma_{h}$ as constants or functions representing non-local features in the hydrodynamic flow, such as the influence of the surface. Earlier models of this kind were developed by 
Deardorff $(1966,1972 a, b)$ for the heat flux with $\Gamma_{h}$ formulated as a function of variances of turbulent virtual potential temperature and turbulent vertical velocity. In the more recent Gayno-Seaman scheme for heat flux, $\Gamma_{h}$ is formulated using surface heat flux and convective vertical velocity $w_{*}=\left[g Z_{i} /\left(\overline{T_{v}}\left(\overline{T_{v}^{\prime} w^{\prime}}\right)_{s}\right)\right]^{1 / 3}$, where $Z_{i}$ is the boundary-layer height and subscript $s$ denotes surface (Han et al. 2009).

These countergradient models are conventionally developed for the convective boundary layers under statically neutral or unstable conditions. However, other studies find countergradient transport occurring under stable conditions as well. Laboratory studies by Komori and Nagata (1996) show countergradient transport of momentum, particularly at large scales, in stably-stratified shear flows. Direct numerical simulations and comparisons with turbulent channel-flow observations by Iida and Nagano (2007) also indicate the presence of persistent countergradient transport in stably-stratified shear flows. Flux-tower measurements by Mahrt and Vickers (2005) indicate that under statically stable conditions, turbulence becomes intermittent with countergradient transport of heat at large scales near the surface. Aircraft observations by Inoue et al. (2005) identify positive heat flux within the statically stable Arctic lower troposphere associated with ice openings, which is indicative of countergradient transport. Various phenomena are suggested to cause countergradient transport of momentum and heat under statically stable conditions. Examples include wavy motions, breaking of waves due to Kelvin-Helmholtz instability (Ohya 2001) and the formation of longitudinal vortical structures that are elongated in the streamwise direction (Iida and Nagano 2007).

The countergradient approach under statically stable conditions is not extensively adopted in models due to a lack of observations and knowledge of adequate parametrizations. However, such an inclusion is very important for two reasons. First, a large portion of the atmosphere above the boundary layer exhibits statically stable conditions, therefore, countergradient transport, if it exists, should occur in a major part of the atmospheric domain. Second, countergradient transport may become more important under static stability since there is a significant decrease in downgradient transport under such conditions (Iida and Nagano 2007). As a result, successful inclusion of a countergradient parametrization for such cases may improve atmospheric model performances significantly.

\subsection{Research Objectives}

Many studies in the literature characterize properties of turbulence under statically stable conditions in boundary layers experimentally, either in laboratory or in the atmosphere using flux towers. However, studies of clear-air turbulence at higher altitudes in the lower troposphere above the boundary layer under very stable conditions are lacking. Even studies that attempt such measurements produce statistics that are informative but not necessarily directly useful for atmospheric model development. For example, Cho et al. (2003) and Dehghan et al. (2014) analyze aircraft measurements of turbulence using structure functions to derive dissipation rates $(\epsilon)$ in clear-air turbulence, and Inoue et al. (2005) measured the heat flux over sea-ice using aircraft observations. However, these statistics do not reliably estimate turbulent diffusion coefficients $\left(K_{m}, K_{h}\right)$, which are relevant to turbulent flux parametrizations in the atmosphere (Hocking 1999). In addition, turbulence measurements using instrumentation on aircraft under stable conditions pose many difficulties due to weak turbulence and non-stationary or heterogeneous conditions. 
To address these needs, we used an aircraft to measure clear-air turbulence in the lower Arctic troposphere near Resolute, Nunavut, Canada, during the summer 2014. The slant profiling technique is used to estimate Reynolds stress, heat flux, and vertical gradients of wind speed and virtual potential temperature. This information is then used to directly derive diffusion coefficients and the turbulent Prandtl number. Additionally, turbulent kinetic energy and dissipation rates are computed. The findings are then used to evaluate expressions for heat flux and turbulent Prandtl number for use in atmospheric modelling.

\section{Experimental Methodology}

The actual campaign was the first of two research aircraft missions in the Arctic as part of the NETCARE (NETwork on Climate and Aerosols: Addressing Key Uncertainties in Remote Canadian Environments) project (www.netcare-project.ca). The aircraft, Polar 6, was a DC-3 converted to a Basler BT-67, from the German Alfred Wegener Institute (AWI). Turbulence measurements were performed during 19 flights, including test, ferry, and research flights around Resolute Bay $\left(74.71^{\circ} \mathrm{N}, 94.97^{\circ} \mathrm{W}\right)$, Nunavut, Canada, from 26 June 2014 to $24 \mathrm{July}$ 2014. Figure 1 and Table 4 show the schedule and tracks for the 11 research flights, which mainly occurred over frozen or open ocean. Each research flight varied in duration, with a total of 52.1 flight hours. The aircraft only occasionally sampled very thin clouds as confirmed by Leaitch et al. (2016) who find only 62 cloud-averaged samples for a total of 1.6 flight hours out of the entire 52.1 flight hours. So, it is expected that properties of clear-air turbulence were measured most of the time.

Fourteen radiosondes were launched during the study campaign from either the weather station in Resolute Bay (ten radiosondes) or from the Amundsen ice-breaker (four radiosondes) around the vicinity of Resolute Bay, in order to provide vertical profiles through the troposphere. Figure 1 and Table 5 show the location for radiosonde launches. The Amundsen locations were $74.24^{\circ} \mathrm{N} 91.52^{\circ} \mathrm{W}, 74.28^{\circ} \mathrm{N} 91.58^{\circ} \mathrm{W}, 74.24^{\circ} \mathrm{N} 92.22^{\circ} \mathrm{W}$, and $74.61^{\circ} \mathrm{N}$ $94.91^{\circ} \mathrm{W}$ for radiosonde launches $11,12,13$, and 14 , respectively. Using the radiosonde data the boundary-layer height $\left(Z_{i}\right)$ is estimated as $275 \pm 164 \mathrm{~m}$ during the campaign. For this estimate the bulk Richardson number is calculated between two heights, one near the surface at 40-m elevation and another at successively increasing elevations, until a critical bulk Richardson number of 0.5 is reached. The boundary-layer height is then approximated as this height. For more details refer to Aliabadi et al. (2016a).

\subsection{State Parameters and Meteorological Measurements}

State and meteorological variables were measured with a sampling frequency of $40 \mathrm{~Hz}$ by the AIMMS-20 instrument, installed under the wing of the Polar 6 aircraft. The instrument was manufactured by Aventech Research Inc., Barrie, Ontario, Canada, and consisted of various modules. The air data probe (ADP) accurately measured the three-dimensional aircraft-relative flow vector (true air speed, angle-of-attack, and sideslip), and a three-axis accelerometer pack facilitated direct measurement of turbulence. The temperature and relative humidity sensors were located in the aft section of the probe for protection. A GPS module provided the aircraft $3 \mathrm{D}$ position and inertial velocity. Horizontal and vertical wind speeds were measured with accuracies of 0.50 and $0.75 \mathrm{~m} \mathrm{~s}^{-1}$, respectively, with a resolution $0.01 \mathrm{~m} \mathrm{~s}^{-1}$, which was two to three orders of magnitude smaller than typical wind speeds. The accuracy and resolution for temperature measurements were 0.30 and $0.01{ }^{\circ} \mathrm{C}$, respectively, and the accuracy and resolution for relative humidity measurement were 2.0 and 


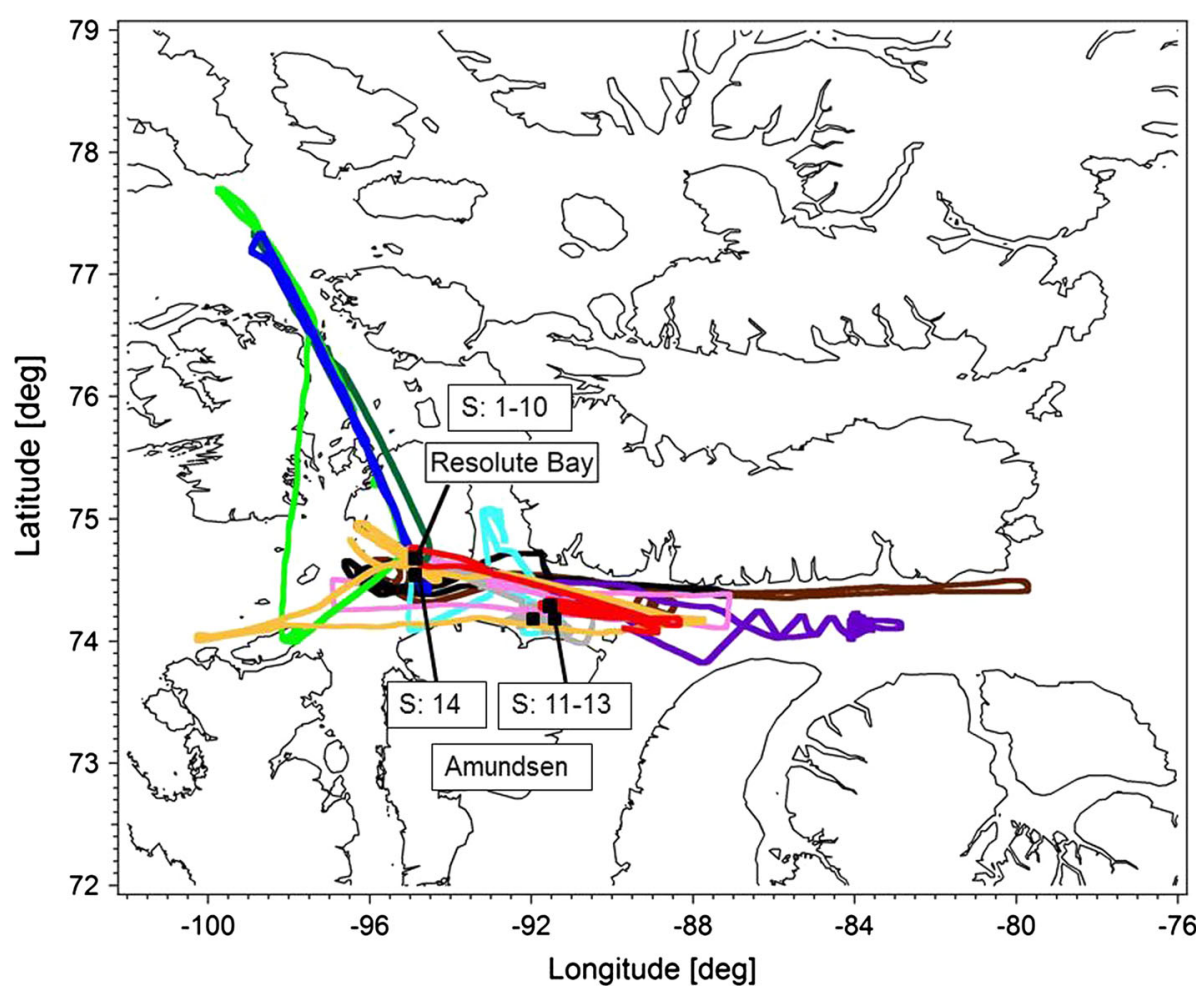

Fig. 1 NETCARE 2014 research flight tracks and radiosonde launching platforms from Resolute Bay (radiosondes S: 1-10) and the Amundsen ice-breaker (radiosondes S: 11-14)

$0.1 \%$, respectively. The mean true air speed during the research flights was $70.9 \pm 6.7 \mathrm{~m} \mathrm{~s}^{-1}$, where the variability is reported with one standard deviation.

\subsection{Aircraft Slant Profiling}

\subsubsection{Stationary versus Moving Probe Measurements}

Turbulent eddies in the atmosphere usually satisfy the Taylor hypothesis (Willis and Deardorff 1976), so that they may be considered frozen as they travel past a sensor (Taylor 1938) under all stability conditions (Geernaert et al. 1987; Ohya 2001). Given that aircraft speeds are usually about one order of magnitude higher than typical wind speeds, it is a good practical assumption to consider equivalence between flux tower (stationary probe) and aircraft (moving probe) turbulence measurements for atmospheric studies.

\subsubsection{Determination of Mean Vertical Gradients}

To determine the vertical variation of state and meteorological parameters, monotonic ascents and descents in aircraft legs are identified given a set of fixed height intervals $(\Delta H=50$, $100,200 \mathrm{~m}$ ). Figure 2 shows an example of a conceptual monotonic ascent, where the height interval and leg length indicate the vertical and horizontal displacements of the aircraft. Table 1 shows the statistics for the vertical and horizontal displacements of the aircraft 


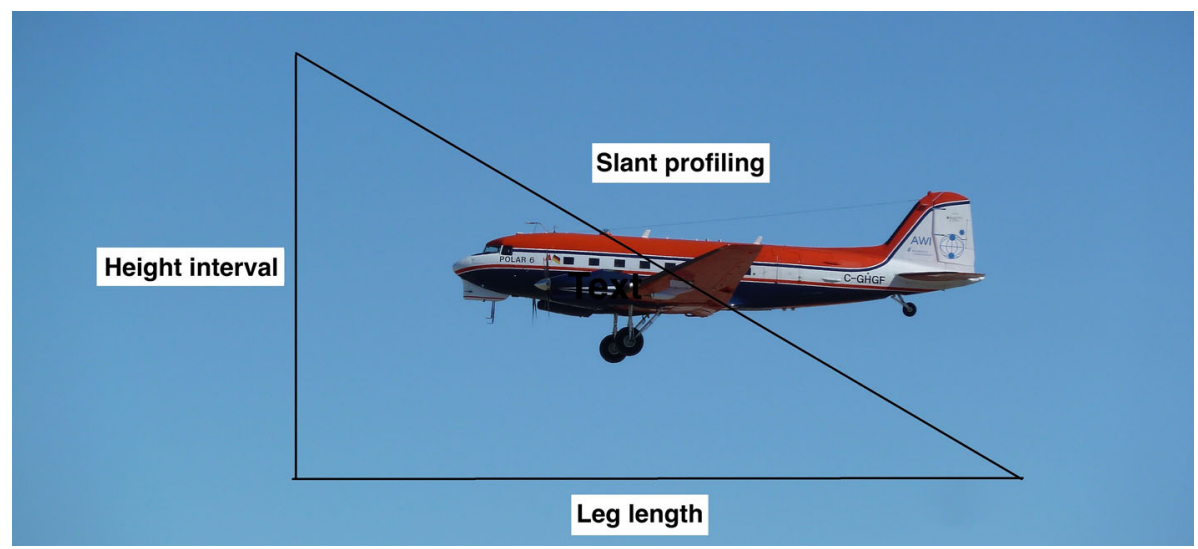

Fig. 2 Slant profiling with the Polar 6 aircraft; a conceptual monotonic ascent is shown with the height interval and leg length identified; the aspect ratio of the height interval versus leg length is not to scale

Table 1 Statistics for flight legs identified using slant profiling technique tabulated as a function of leg height interval $(\Delta H)$

\begin{tabular}{llll}
\hline & No. of legs (QC legs) & Avg. leg time (s) & Avg. leg length (m) \\
\hline$\Delta H=50 \mathrm{~m}$ & $4254(1743)$ & $18 \pm 8$ & $1365 \pm 638$ \\
$\Delta H=100 \mathrm{~m}$ & $1984(903)$ & $35 \pm 11$ & $2630 \pm 920$ \\
$\Delta H=200 \mathrm{~m}$ & $920(467)$ & $71 \pm 14$ & $5304 \pm 1353$ \\
\hline
\end{tabular}

associated with each height interval. These height intervals are chosen because they are representative of a typical vertical resolution in operational weather forecast models. One limitation of this study, however, is that the associated horizontal distances are smaller than typical horizontal resolution in models by a factor of two to five (Aliabadi et al. 2016a).

Knowledge of vertical gradients of mean horizontal wind speed and virtual potential temperature with high certainty is essential since these gradients frequently appear in expressions that formulate turbulent fluxes (for example Eqs. 5-9). For this purpose, these gradients are determined by fitting a line to each profile. Since some profiles are contaminated by mesoscale and large-scale atmospheric fluctuations, profiles are quality controlled (QC) for linear fits with a coefficient of determination $\left(R^{2}\right)>0.5$. Profiles with $R^{2}<0.5$ are discarded. For the selected height intervals a number of statistics are identified and shown in Table 1; the legs occurred in an altitude range from 150 to $3000 \mathrm{~m}$.

\subsubsection{Determination of Systematic and Random Errors in Turbulence Measurements}

Ensemble averaged turbulent variances and fluxes are approximated by a finite sample over a finite time period using time averaging. The systematic and random errors, which arise from time averaging instead of ensemble averaging, are estimated using the methodology of Lenschow et al. (1994). We estimate these errors using aircraft measurements from the longest flight legs. Random errors are not biased, but the systematic errors discussed here always result in underprediction of variances or magnitude of the turbulent fluxes, either positive or negative. 
The second-order moments for variances of vertical wind and virtual potential temperature fluctuations are represented by $\mu_{2}$, and the second-order moments for heat flux and Reynolds stress are represented by $F$. Note that subscripts $w, u, \theta_{v}, u w$, and $\theta_{v} w$ for these moments are not shown for notational convenience. These moments are approximated by time averaging over a finite time $(T)$ and represented by $\mu_{2}(T)$ and $F(T)$, respectively. The systematic error $(S E)$ and the random error $(R E)$ estimates for variances and fluxes are given by

$$
\begin{aligned}
& S E=\frac{\mu_{2}-<\mu_{2}(T)>}{\mu_{2}}=2 \frac{\tau}{T}, \\
& S E=\frac{F-<F(T)>}{F}=2 \frac{\tau}{T}, \\
& R E=\frac{\sqrt{<\left[\mu_{2}(T)-<\mu_{2}(T)>\right]^{2}>}}{\mu_{2}}=\sqrt{2 \frac{\tau}{T}}, \\
& R E=\frac{\sqrt{<[F(T)-<F(T)>]^{2}>}}{|F|}=\sqrt{2 \frac{\tau}{T}},
\end{aligned}
$$

where $\tau$ is the integral time scale corresponding to the variances and fluxes of interest, and it is assumed that $\tau \ll T$. The integral time scale can be calculated if well-behaved normalized autocorrelation functions $\left(R_{a b}\right)$ can be computed so that $\tau_{a b}=\int_{0}^{\infty} R_{a b}(t) d t$. For a discretized time series, the autocorrelation function is computed using the expression

$$
\begin{aligned}
& R_{a b}(j) \\
& =\frac{\sum_{k=0}^{N-j-1}\left[\left(a_{k}-\bar{a}_{k}\right)\left(b_{k+j}-\bar{b}_{k+j}\right)\right]}{\left[\sum_{k=0}^{N-j-1}\left[\left(a_{k}-\bar{a}_{k}\right)\left(b_{k}-\bar{b}_{k}\right)\right]\right]^{1 / 2}\left[\sum_{k=0}^{N-j-1}\left[\left(a_{k+j}-\bar{a}_{k+j}\right)\left(b_{k+j}-\bar{b}_{k+j}\right)\right]\right]^{1 / 2}},
\end{aligned}
$$

where the total time series with a sampling time of $\Delta t$ contains $N$ data points and autocorrelation is computed for a time lag of $t_{2}-t_{1}=j \Delta t$ over the entire time series. Averages for $k$ and $k+j$ indices are calculated using $\bar{x}_{k}=\frac{1}{N-j} \sum_{k=0}^{N-j-1} x_{k}$ and $\bar{x}_{k+j}=\frac{1}{N-j} \sum_{k=0}^{N-j-1} x_{k+j}$.

Figure 3 shows the well-behaved computed normalized autocorrelations for the determination of integral time scales except for $R_{\theta_{v} \theta_{v}}$ and $R_{\theta_{v} w}$. Autocorrelation functions are computed without high-pass filtering of input data to ensure that all scales of fluctuations less than the flight leg length are accounted for. $R_{w w}$ and $R_{u u}$ start near unity and decrease to zero by about $10 \mathrm{~s}$ and $40 \mathrm{~s}$, respectively. $R_{u w}$ starts from unity and decreases to zero by about $35 \mathrm{~s}$, but it decreases more slowly initially. $R_{\theta_{v} \theta_{v}}$ and $R_{\theta_{v} w}$ are usually difficult to calculate due to the presence of thermal structures in the atmosphere, hence in practice $\tau_{w w}$ and $\tau_{u w}$ are multiplied by a factor of 1.5 to provide conservative estimates for $\tau_{\theta_{v} \theta_{v}}$ and $\tau_{\theta_{v} w}$ (Lenschow et al. 1994). With these considerations we estimate the integral time scales, by integrating autocorrelations, as $\tau_{w w}=3.6 \mathrm{~s}, \tau_{u u}=11.9 \mathrm{~s}, \tau_{u w}=20.8 \mathrm{~s}, \tau_{\theta_{v} w}=31.21 \mathrm{~s}$, and $\tau_{\theta_{v} \theta_{v}}=5.4 \mathrm{~s}$. Our values for variances and fluxes are by a factor of 3 and 20 , respectively, higher than those determined by Lenschow et al. (1994) within the convective boundary layer in mid latitudes. This is expected since intermittent turbulence, which accounts for a large amount of energy transfer under stable conditions, occurs at larger scales. These integral time scales provide estimates for percent systematic and random errors for single measurements $(n=1)$ and multiple measurements $(n=20)$ in Table 2.

These errors are not insignificant and in the ideal situation longer flight legs would have been necessary to reduce them. However, our unique approach to measure a large number of profiles at each height or stability condition $(R i)$ helps to reduce the random errors sub- 


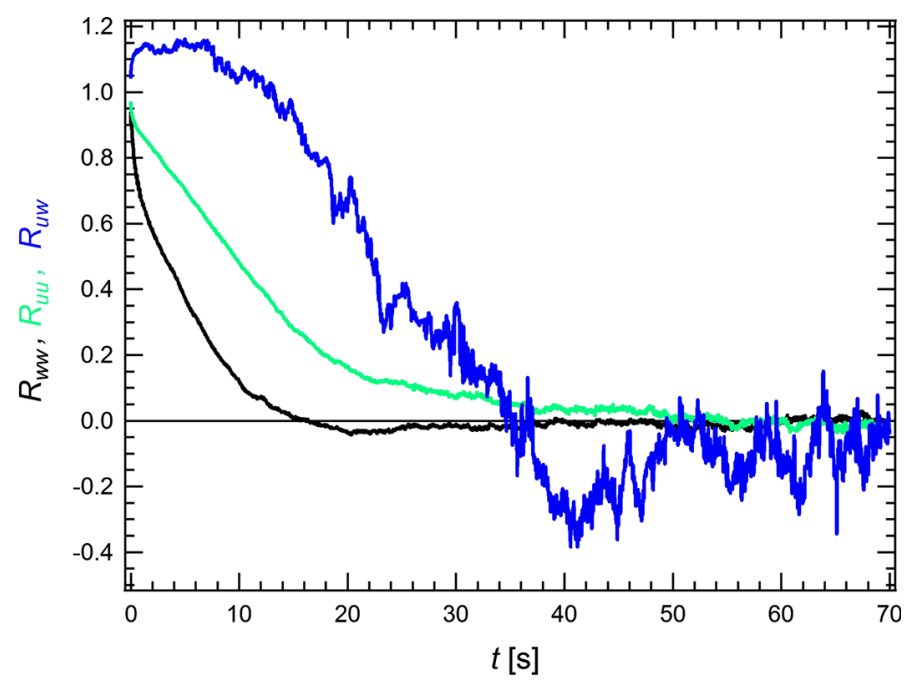

Fig. 3 Median normalized autocorrelation functions for non-filtered signals computed for all flight legs $(\Delta H=200 \mathrm{~m})$

Table 2 Estimates for percent systematic and random errors in turbulence measurements as a function of number of measurements $(n)(\Delta H=200 \mathrm{~m})$

\begin{tabular}{lllllllll}
\hline & $S E_{w w}$ & $R E_{w w}$ & $S E_{\theta_{v} \theta_{v}}$ & $R E_{\theta_{v} \theta_{v}}$ & $S E_{u w}$ & $R E_{u w}$ & $S E_{\theta_{v} w}$ & $R E_{\theta_{v} w}$ \\
\hline$n=1$ & 10 & 32 & 15 & 39 & 59 & 77 & 88 & 94 \\
$n=20$ & 10 & 7.1 & 15 & 8.7 & 59 & 17 & 88 & 21 \\
\hline
\end{tabular}

stantially. We present results in 20 bins centred around specific heights or stability parameter (Ri). For $\Delta H=200 \mathrm{~m}$, each bin contains $n \approx 20$ measurements, given the number of quality controlled legs in Table 1 . Therefore, the random errors for the quartiles in each bin should reduce by a factor of $1 / \sqrt{n} \approx 1 / \sqrt{20}$.

To minimize the errors, we report the majority of our analyses performed for height intervals of $\Delta H=200 \mathrm{~m}$. This choice also corresponds to a typical vertical resolution within the lower troposphere for operational weather forecast models. Where appropriate, results are also shown for $\Delta H=50$ or $100 \mathrm{~m}$ to demonstrate single profiles in Sect. 4.1 or for the purpose of sensitivity analysis in Sect. 4.5. Throughout the following analyses we apply a correction for the calculated systematic errors.

\subsection{Cut-off Frequency and the Spectral Properties of Turbulence}

To calculate turbulence quantities for each leg, a high-pass filter with a cut-off frequency of $f_{c}=0.025 \mathrm{~Hz}$ is used to remove mesoscale variations in the signals. This excludes atmospheric fluctuations greater than about $3.2 \mathrm{~km}$ in length, based on the average aircraft speed. This cut-off frequency is close to that used in other turbulence measurements using aircraft in stable conditions at mid latitudes by Lenschow et al. (1988) $\left(f_{c}=0.01 \mathrm{~Hz}\right)$. We report the majority of our results using this cut-off frequency, however, in Sect. 4.5 a sensitivity analysis is also performed and reported to show the effect of varying $f_{c}$ from 0.0125 to $0.2 \mathrm{~Hz}$. 
Turbulent dissipation rate $(\epsilon)$ for each leg is calculated using structure functions based on the methodology of Hocking (1999) and Dehghan et al. (2014). Spectral analysis is performed for the heat flux using fast Fourier transform (FFT) (Stull 2003).

\section{Turbulent-Flux Parametrization}

We propose a framework to parametrize the heat flux, and the Reynolds stress (through the parametrization of the turbulent Prandtl number), for use in 1.5-order turbulence closure schemes. For this purpose we develop three parametrizations for the heat flux using its budget equation with increasing level of simplification. Assuming horizontal homogeneity and no subsidence, the transport equation for the heat flux is given as (Stull 2003)

$$
\underbrace{\frac{\partial \overline{\theta_{v}^{\prime} w^{\prime}}}{\partial t}}_{\mathrm{I}}=\underbrace{-\overline{w^{\prime 2}} \frac{\partial \overline{\theta_{v}}}{\partial z}}_{\mathrm{XI}} \underbrace{-\frac{\partial \overline{\theta_{v}^{\prime} w^{\prime} w^{\prime}}}{\partial z}}_{\mathrm{IV}}+\underbrace{\overline{\theta^{\prime} \theta_{v}^{\prime} \frac{g}{\overline{\theta_{v}}}}}_{\mathrm{V}} \underbrace{+\frac{1 \overline{\bar{\rho}}}{P^{\prime} \frac{\partial \theta_{v}^{\prime}}{\partial z}}}_{\mathrm{VIII}} \underbrace{-2 v \overline{\left(\frac{\partial w^{\prime}}{\partial z}\right)\left(\frac{\partial \theta_{v}^{\prime}}{\partial z}\right)}}_{\mathrm{X}},
$$

where terms, from left to right, are labeled storage (I), production or consumption by mean potential temperature gradient (XI), transport by turbulent motion (IV), production by buoyancy $(\mathrm{V})$, pressure redistribution (VIII), and dissipation $(\mathrm{X})$ with $v$ representing the kinematic viscosity of air (Stull 2003). We keep the numbering of these terms consistent with the original equation provided by Stull (2003), which is for general conditions and includes more terms. Assuming the quasi-steady-state condition for heat flux and neglecting terms IV for simplicity and term $\mathrm{X}$ for being insignificant compared to other terms, which are to be discussed in detail in Sect. 4.4, we obtain

$$
0=-\overline{w^{\prime 2}} \frac{\partial \overline{\theta_{v}}}{\partial z}+\overline{\theta^{\prime} \theta_{v}^{\prime}} \frac{g}{\overline{\theta_{v}}}+\frac{1}{\bar{\rho}} \overline{P^{\prime} \frac{\partial \theta_{v}^{\prime}}{\partial z}} .
$$

Term V may be approximated as $C g \frac{\overline{\theta_{v}^{\prime 2}}}{\overline{\theta_{v}}}$ (Yamada and Mellor 1975), where $C$ is a constant that shall be fitted experimentally. Term VIII may also be simplified to $-\frac{q}{3 l_{h}} \overline{\theta_{v}^{\prime} w^{\prime}}$ (Rotta 1951), where $l_{h}$ is a mixing length for heat and $q^{2}=\overline{u^{\prime 2}}+\overline{v^{\prime 2}}+\overline{w^{\prime 2}}$ is twice the turbulent kinetic energy (e) (Mellor 1973). Rearranging these terms for heat flux we obtain

$$
\overline{\theta_{v}^{\prime} w^{\prime}}=\frac{3 l_{h}}{q}\left(-\overline{w^{\prime 2}} \frac{\partial \overline{\theta_{v}}}{\partial z}+C g \frac{\overline{\theta_{v}^{\prime 2}}}{\overline{\theta_{v}}}\right),
$$

which accounts for anisotropic turbulence in the $z$ direction, and both downgradient and countergradient transport of heat. This is true since under statically stable conditions $\left(\frac{\partial \overline{\theta_{v}}}{\partial z}>0\right)$, term $\left(-\overline{w^{\prime 2}} \frac{\partial \overline{\theta_{v}}}{\partial z}\right)$ is always negative, contributing to downgradient transport, while term $\left(C g \frac{\overline{\theta_{v}^{\prime 2}}}{\overline{\theta_{v}}}\right)$ is always positive with $C>0$, contributing to countergradient transport. We call this formulation Parametrization 1 for the heat flux. Now we explicitly assume that turbulence is isotropic to arrive at a more simplified parameterization. Turbulent fluctuations of wind speed $\left(u^{\prime}, v^{\prime}, w^{\prime}\right)$ are statistically similar in all directions in the case of isotropic turbulence, allowing us to replace $\overline{w^{\prime 2}}$ with $q^{2} / 3$, to obtain

$$
\overline{\theta_{v}^{\prime} w^{\prime}}=\frac{3 l_{h}}{q}\left(-\frac{q^{2}}{3} \frac{\partial \overline{\theta_{v}}}{\partial z}+C g \frac{\overline{\theta_{v}^{\prime 2}}}{\overline{\theta_{v}}}\right),
$$


as Parametrization 2. We can further simplify this expression by ignoring the countergradient term to arrive at the familiar downgradient heat flux formulation

$$
\overline{\theta_{v}^{\prime} w^{\prime}}=-l_{h} q \frac{\partial \overline{\theta_{v}}}{\partial z}
$$

as Parametrization 3. The three formulations for heat flux provide parametrizations with increasing level of simplification. For example, the first parametrization requires additional knowledge of both vertical velocity variance $\left(\overline{w^{\prime 2}}\right)$ and variance of virtual potential temperature $\left(\overline{\theta_{v}^{\prime 2}}\right)$, while the third parametrization only requires knowledge of the turbulent kinetic energy and mixing length to formulate heat flux. In light of this development, the parameterizations give Eqs. 10 and 6 as

$$
\begin{aligned}
& \overline{\theta_{v}^{\prime} w^{\prime}}=-\underbrace{\frac{3 l_{h} \overline{w^{\prime 2}}}{q}}_{K_{h}}(\frac{\partial \overline{\theta_{v}}}{\partial z}-\underbrace{\frac{C g}{\overline{w^{\prime 2}}} \frac{\overline{\theta_{v}^{\prime 2}}}{\overline{\theta_{v}}}}_{\Gamma_{h}}), \\
& \overline{\theta_{v}^{\prime} w^{\prime}}=-\underbrace{l_{h} q}_{K_{h}}(\frac{\partial \overline{\theta_{v}}}{\partial z}-\underbrace{\frac{3 C g}{q^{2}} \frac{\overline{\theta_{v}^{\prime 2}}}{\overline{\theta_{v}}}}_{\Gamma_{h}}), \\
& \overline{\theta_{v}^{\prime} w^{\prime}}=-\underbrace{l_{h} q}_{K_{h}} \frac{\partial \overline{\theta_{v}}}{\partial z} .
\end{aligned}
$$

From any of the parametrizations above, and knowledge of the turbulent Prandtl number, the most convenient approach to calculate Reynolds stress is using Eq. 7. In such a case, the analytical development to derive a parametrization for Reynolds stress using its budget equation is not necessary. This approach, however, is limited for a number of situations. The stable boundary layer can support gravity waves that cause non-zero Reynolds stress but zero heat flux. For such a situation, the turbulent Prandtl number is undefined. Because gravity waves are ubiquitous in the stable boundary layer, they must always be assumed present and active in the vertical redistribution of kinetic energy and momentum. Atmospheric models usually enforce minimum values for turbulent kinetic energy or momentum diffusivity throughout the vertical domain (Makar et al. 2014).

This development allows for an experimental examination of turbulent fluxes and turbulent Prandtl number in the lower troposphere to investigate the success of the above parametrizations in predicting turbulent fluxes under statically stable conditions.

\section{Results and Discussion}

Figure 4 shows vertical profiles of virtual potential temperature $\left(\theta_{v}\right)$ measured by the radiosondes; the height is normalized by the boundary-layer height $\left(Z_{i}\right)$. For many soundings an intermediate stable layer, or sometimes multiple stable layers, appear(s) above $Z_{i}$ and below the very stable layer aloft up to $\frac{Z}{Z_{i}} \approx 10$. Similar features were observed by Aliabadi et al. (2016a) in Barrow, Alaska where there is no definite step change in the vertical shape of $\theta_{v}$ from $Z_{i}$ to the very stable layer aloft; rather, there is a gradual transition between estimated $Z_{i}$ and the stable layer aloft (see reference for discussion). During most flight legs, the lower 


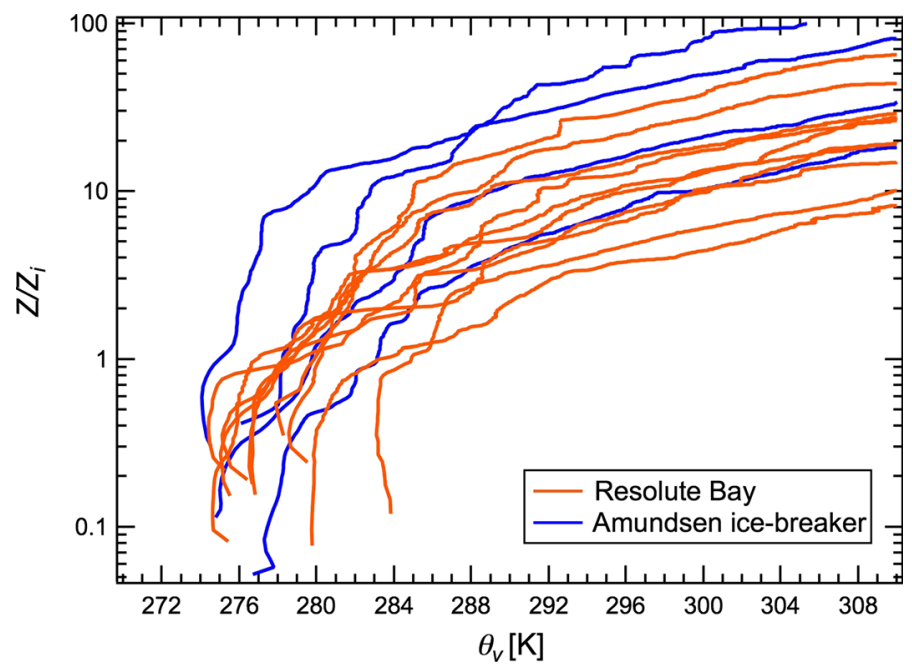

Fig. 4 Vertical profiles of virtual potential temperature as measured with radiosondes launched from Resolute Bay or the Amundsen during the NETCARE 2014 campaign

troposphere in the Arctic exhibits strong stability with a positive vertical gradient for virtual potential temperature profiles that passed the quality control test for linearity described in Sect. 2.2.2. The vertical gradient for horizontal wind speed, however, can be either positive or negative.

\subsection{Downgradient and Countergradient Transport for Individual Flight Legs}

Figure 5 shows evidence for both downgradient and countergradient transport of momentum and heat for selected individual profiles. By the definition of downgradient transport (Eqs. 5 and 6), if a profile of wind speed or virtual potential temperature exhibits a positive vertical gradient, the downgradient turbulent fluxes must be negative and scatter plots for $\theta_{v}^{\prime}-w^{\prime}$ or $u^{\prime}-w^{\prime}$ should show activity in the second and fourth quadrants (note: our definition of quadrants are as follows: 1 for top-right, 2 for top-left, 3 for bottom-left, and 4 for bottom-right). If a profile exhibits a negative vertical gradient, the downgradient turbulent fluxes should show activity in the first and third quadrants. For countergradient transport, the opposite occurs.

The two selected profiles exhibit positive vertical gradients for wind speed and virtual potential temperature. As a result, for the downgradient case, the fluxes show activity in quadrants 2 and 4 (Fig. 5c, e), while for the countergradient case, the fluxes show activity in quadrants 1 and 3 (Fig. 5d, f). There appear accumulated clusters of points in the quadrant plots. This is caused by the limited sampling time interval, where only few eddies, each corresponding to a cluster of points, are detected for each leg. The time series for fluxes in Fig. $5 \mathrm{~g}, \mathrm{~h}$ show examples of detected eddies that can be associated with the quadrant plots.

Figure 6 shows an example time series on 8 July 2014 when the aircraft ascended close to $3000 \mathrm{~m}$ altitude and descended to $200 \mathrm{~m}$ altitude. Heat fluxes and diffusion coefficients are calculated corresponding to a slant profile at a given altitude. The heat flux is negative near the ground but becomes positive at higher altitudes, indicating countergradient transport aloft. This results in positive apparent diffusion coefficients using 
(a)

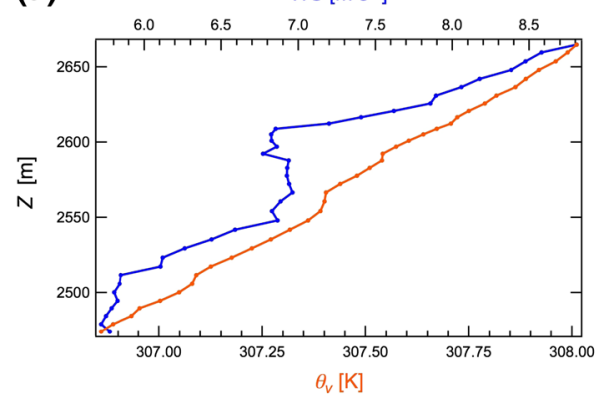

(c)

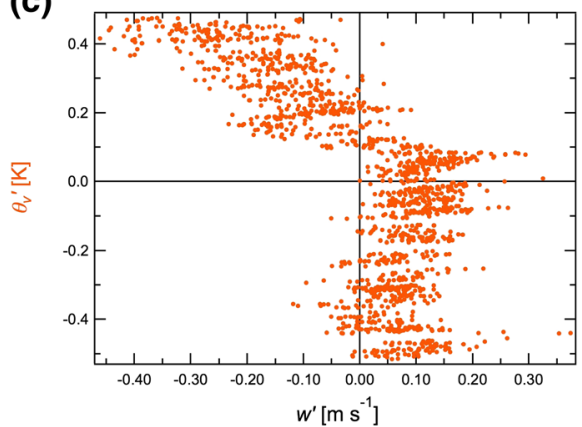

(e)

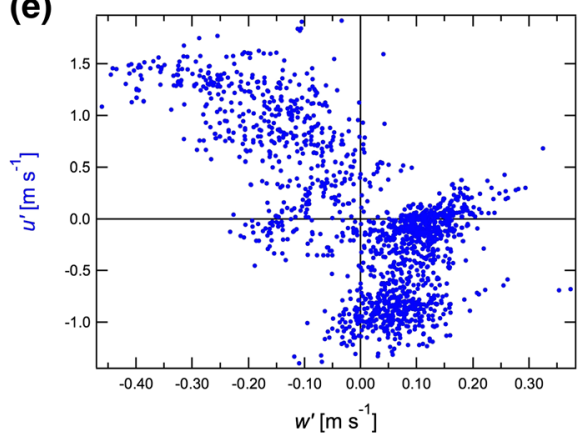

(g)

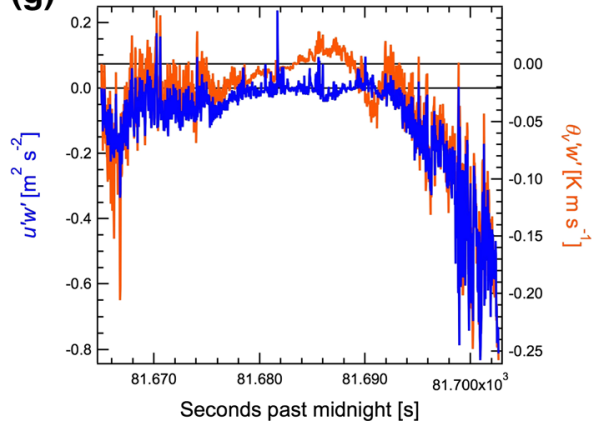

(b)

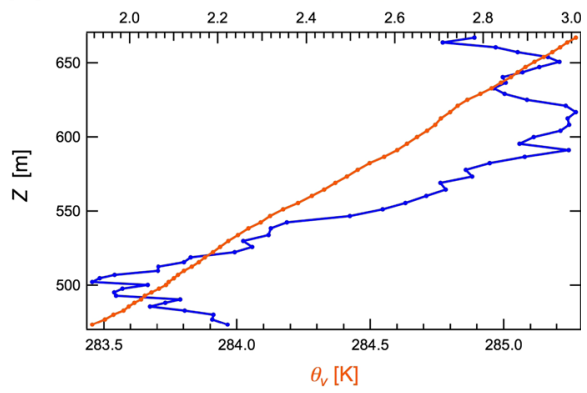

(d)

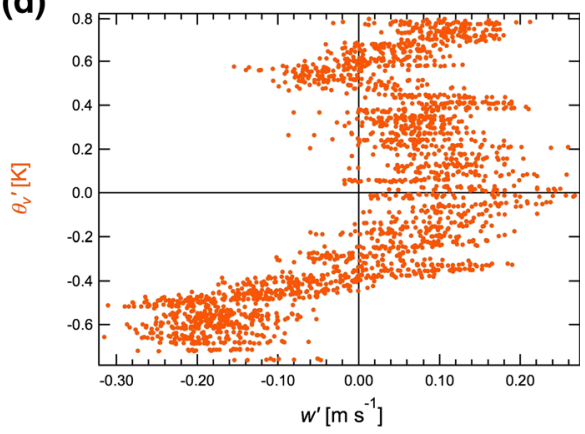

(f)

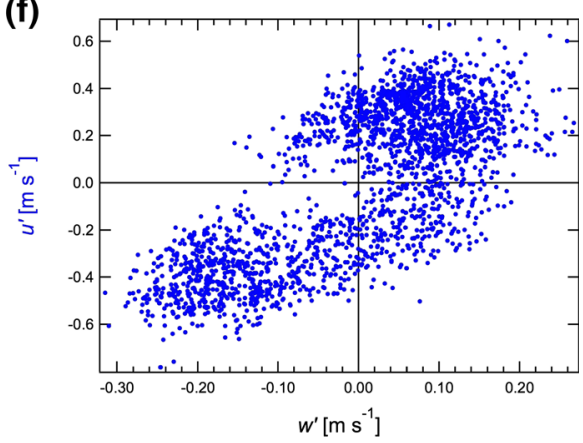

(h)

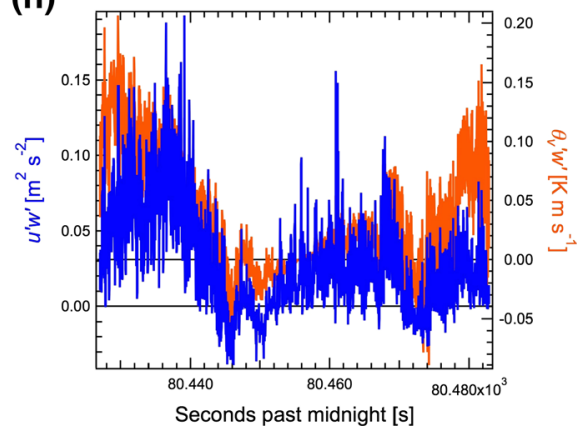

Fig. 5 Vertical profiles of mean virtual potential temperature and horizontal wind speed (a, b); quadrant plots representing heat flux $(\mathbf{c}, \mathbf{d})$ and Reynolds stress $(\mathbf{e}, \mathbf{f})$; time series representing turbulent fluxes $(\mathbf{g}, \mathbf{h})$; downgradient case $(\mathbf{a}, \mathbf{c}, \mathbf{e}, \mathbf{g})$ and countergradient case $(\mathbf{b}, \mathbf{d}, \mathbf{f}, \mathbf{h})$ for individual flight legs $(\Delta H=200 \mathrm{~m}$, $\left.f_{c}=0.025 \mathrm{~Hz}\right)$ 

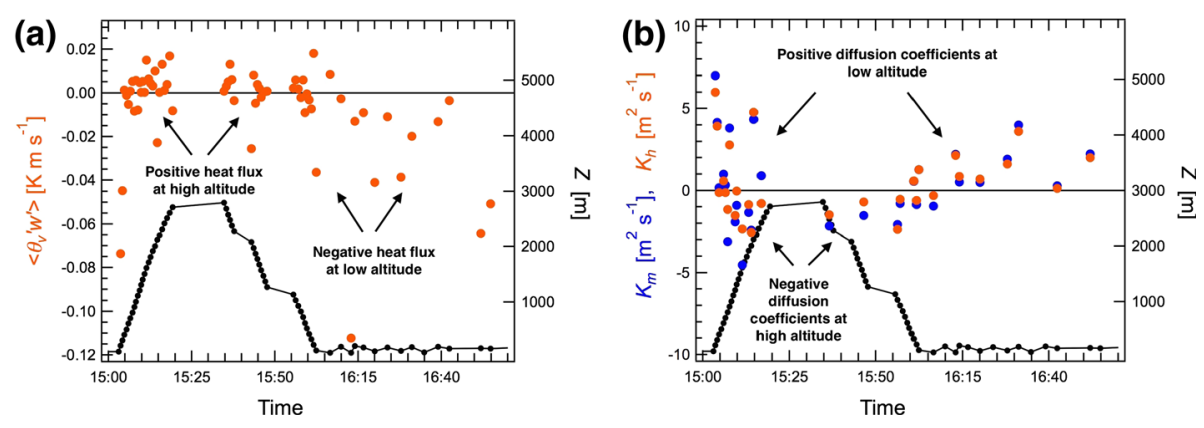

Fig. 6 Heat flux (a) and diffusion coefficients calculated using Eqs. 5 and 6 (b) for a time period on 8 July 2014 where the aircraft ascended close to $3000 \mathrm{~m}$ altitude and descended to $200 \mathrm{~m}$ altitude $(\Delta H=100 \mathrm{~m}$, $f_{c}=0.025 \mathrm{~Hz}$ ); each calculated flux or diffusion coefficient corresponds to a slant profile at a given altitude

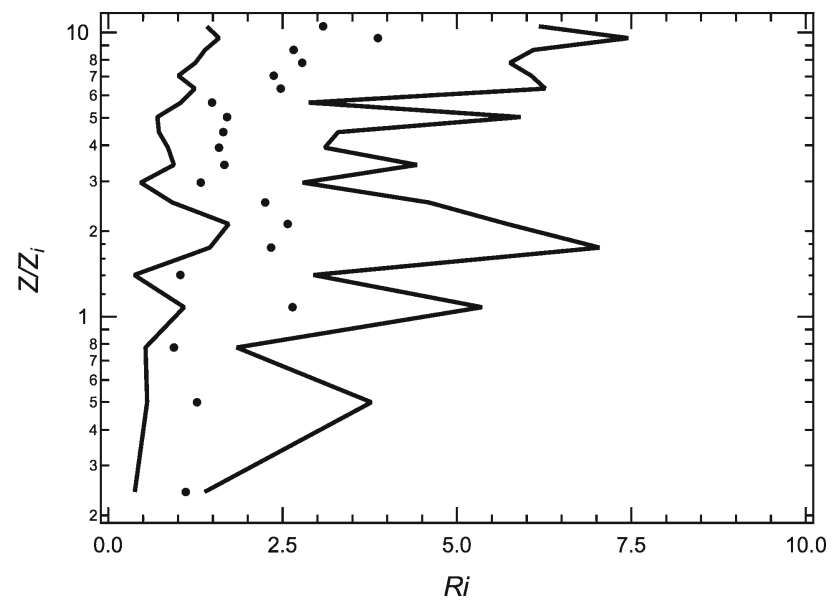

Fig. 7 Vertical profile of the gradient Richardson number $(R i)$; the lines indicate 25th and 75th percentiles and the markers indicate medians

Eqs. 5 and 6 near the ground but negative coefficients aloft using the same equations. During most of this time period the aircraft flew over sea ice, with no correlations observed between turbulent fluxes and surface type changes (i.e. sea ice, leads, polynyas or other terrains).

\subsection{Variation of Turbulent Quantities as a Function of Normalized Altitude or Stability Criteria}

Due to lack of a diurnal cycle in the Arctic, turbulent quantities should be independent of the diurnal period and can be plotted versus normalized height (normalized by the boundarylayer height) or a stability parameter such as the gradient Richardson number $(R i)$ to provide characteristics of the troposphere during the polar day under more general conditions (Aliabadi et al. 2015). Figure 7 gives the vertical variation in stability parameter $(R i)$, indicating increasing stability with altitude.

Figure 8 shows vertical profiles of heat flux, Reynolds stress, heat diffusivity, and momentum diffusivity. The heat flux is negative within the boundary layer but has a tendency toward 
(a)

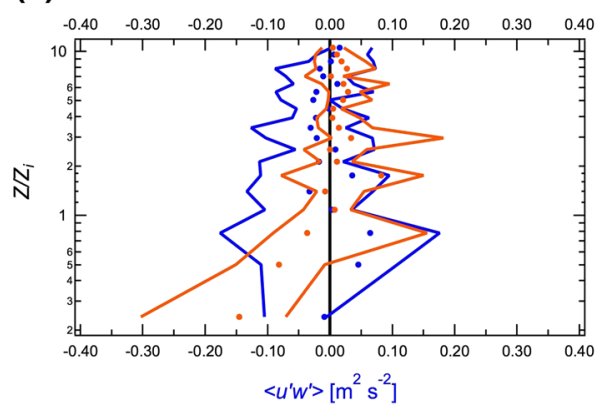

(c)

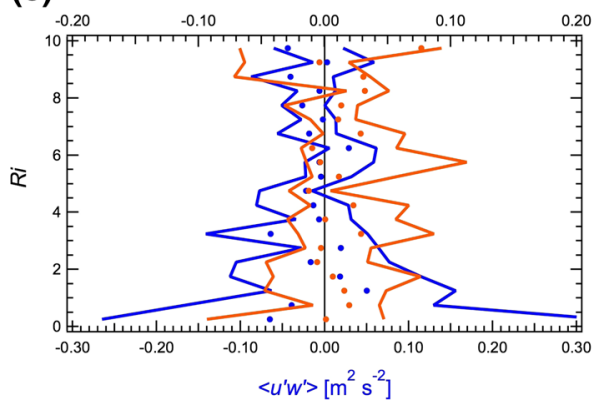

(b)

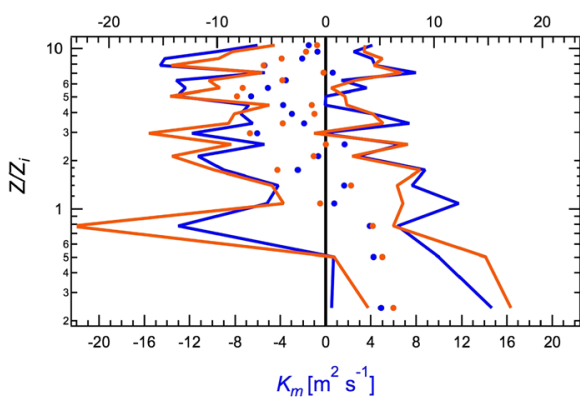

(d)

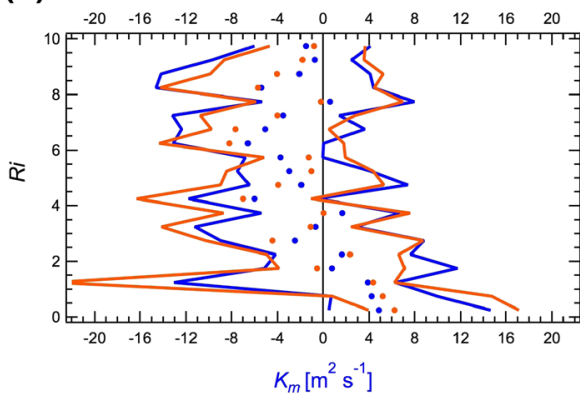

Fig. 8 Heat flux and Reynolds stress profiles (a), diffusion coefficient profiles (b), heat flux and Reynolds stress as a function of Richardson number (c), diffusion coefficient as a function of Richardson number (d) $\left(\Delta H=200 \mathrm{~m}, f_{c}=0.025 \mathrm{~Hz}\right)$; the lines indicate 25 th and 75 th percentiles while the markers indicate medians

positive values with increasing height. Since most legs exhibit statically stable conditions with positive vertical gradients in virtual potential temperature, the positive heat flux is indicative of countergradient transport. This consequently results in the diffusivity, calculated using Eqs. 5 and 6, to show a tendency toward negative values with increasing height or $R i$. The profile for Reynolds stress does not show a systematic shift, because vertical gradients for wind speed can be positive or negative, with countergradient transport of momentum having the same likelihood of being positive or negative. The profiles of heat and momentum diffusivity are very similar, indicating that similar downgradient or countergradient mechanisms for transport occur for both heat and momentum.

The magnitude of countergradient heat flux above the boundary layer in this study can be compared to aircraft observations of the magnitude of downgradient heat flux in convective boundary layers in lower latitudes. Our estimates are comparable to near-surface observations and observations near the top of convective boundary layers. For example, measurements by Bélair et al. (1999) give $0.08 \mathrm{~K} \mathrm{~m} \mathrm{~s}^{-1}$ near the surface and $0.02 \mathrm{~K} \mathrm{~m} \mathrm{~s}^{-1}$ near the top of the convective boundary layer for the Montreal-96 Experiment on Regional Mixing and Ozone (MERMOZ).

Turbulent kinetic energy $(e)$, dissipation rate $(\epsilon)$, and mixing lengths are also quantified. To estimate the dissipation rate using the methodology of Dehghan et al. (2014), the secondorder structure function $\left(D_{L}(r)\right)$ is calculated from the time series of

$$
D_{L}(r)=\overline{\left[U_{L}\left(t+\frac{r}{\overline{V_{a}}}\right)-U_{L}(t)\right]^{2}},
$$


where $U_{L}$ is the horizontal wind-velocity component parallel to aircraft heading, $\overline{V_{a}}$ is aircraft mean horizontal speed during each leg, and $r$ is a length scale within the inertial subrange of energy cascade. Then the dissipation rate and the second-order structure function are related by

$$
D_{L}(r)=C_{d} r^{2 / 3} \epsilon^{2 / 3}
$$

where $C_{d}$ is close to 2.0. The average dissipation rate is estimated by considering a range for $r$ from 200 to $800 \mathrm{~m}$. This is justified because there is a linear relationship between $\log \left(D_{L}(r)\right)$ versus $\log (r)$ in this range of length scales, which indicates the presence of inertial subrange in the energy cascade.

Mixing lengths are calculated for momentum and heat separately according to Kim and Mahrt (1992) as

$$
\begin{gathered}
l_{m}=\sqrt{\left|\frac{K_{m}}{\partial \bar{U} / \partial z}\right|}, \\
l_{h}=\sqrt{\left|\frac{K_{h}}{\partial \bar{U} / \partial z}\right|} .
\end{gathered}
$$

Figure 9 shows these quantities. Turbulent kinetic energy and dissipation rate show higher magnitudes within the boundary layer $\left(Z / Z_{i}<1\right)$, which is also characterized by reduced stability $(0<R i<4)$, and decrease by a factor of two to four in the free troposphere, but they do not vanish with increasing height. Mixing lengths for momentum and heat are similar and slightly increase with height but appear to reach an asymptotic limit. Mixing lengths also show variations as a function of gradient Richardson number $(R i)$, where increasing stability $(R i>4)$ increases the mixing length. This is unlike the predictions of Kim and Mahrt (1992).

Our estimates of turbulent kinetic energy, dissipation rate, and mixing lengths can be compared to observations in lower latitudes. Our estimate of the median turbulent kinetic energy within the boundary layer is one order of magnitude less compared to aircraft observations in the convective boundary layer. For example, measurements by Bélair et al. (1999) give the range 1.5-2.2 $\mathrm{m}^{2} \mathrm{~s}^{-2}$ in MERMOZ. Our estimate of the dissipation rate within the stable boundary layer is about the same order of magnitude as previous aircraft observations near and above the top of the boundary layer in mid-latitudes. For example, measurements by Dehghan et al. (2014) give the range $0.1-1.5 \times 10^{-3} \mathrm{~m}^{2} \mathrm{~s}^{-3}$ for altitude range $0.5-12 \mathrm{~km}$ around the O-QNet radar network, located in south-western Ontario, Canada. Our estimate of the median mixing length in the mostly statically stable troposphere is in the same order of magnitude compared to other observations under statically stable conditions. For example, Kim and Mahrt (1992) give the range 2-14 m as reported in various other studies.

These results suggest that countergradient momentum and heat transport is observed in the very stable free troposphere and they become more important under such conditions because their magnitude can be equivalent or higher than downgradient heat and momentum transport. As a result, their inclusion in relevant parametrizations is important and may improve performance of atmospheric models.

\subsection{Spectral Analysis of Heat Flux}

To investigate spatial and temporal scales of instabilities that cause counter-gradient transport, cospectral analysis of the heat flux is performed. The wavenumber is calculated using

$$
\kappa=\frac{2 \pi}{\lambda}=\frac{2 \pi f}{\overline{V_{a}}},
$$


(a)

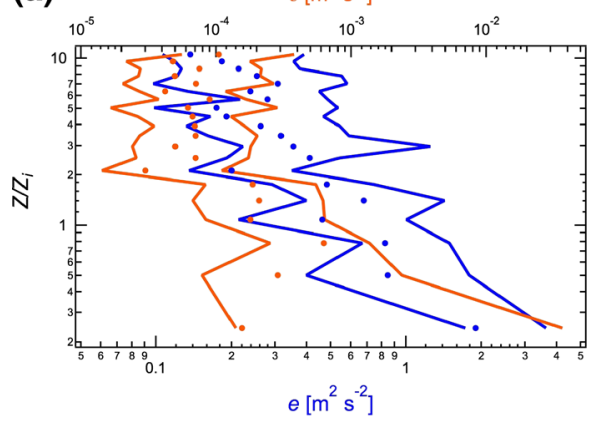

(c)

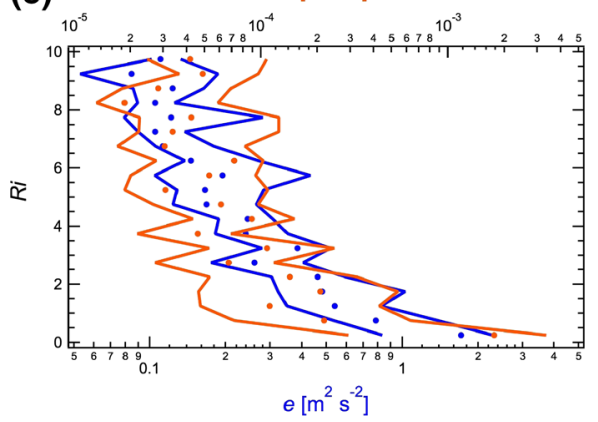

(b)

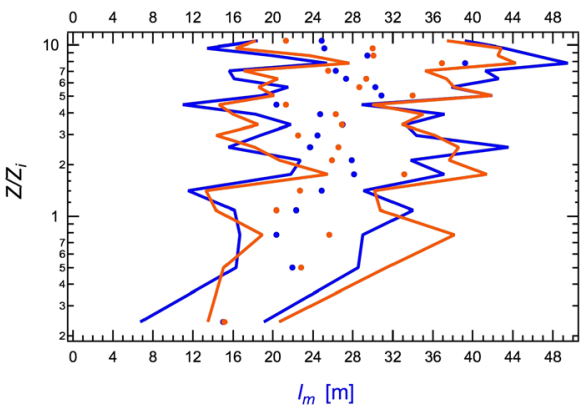

(d)

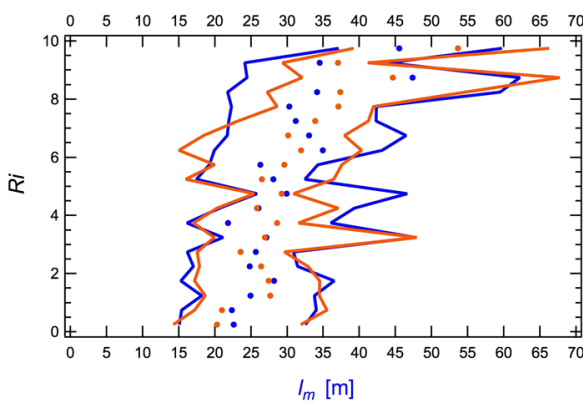

Fig. 9 Turbulent kinetic energy and dissipation rate profiles (a), mixing length profiles (b), turbulent kinetic energy and dissipation rate as a function of Richardson number (c), mixing length as a function of Richardson number $(\mathbf{d})\left(\Delta H=200 \mathrm{~m}, f_{c}=0.025 \mathrm{~Hz}\right)$; the lines indicate 25 th and 75 th percentiles and the markers indicate medians; turbulent kinetic energy and dissipation rate show higher magnitudes within the boundary layer $\left(h<Z_{i}\right)$ and under weak stability $(R i<2)$; mixing lengths increase with height and stability

where $f$ is frequency (Hz) (Dehghan et al. 2014). Figure 10 shows the absolute value of the cospectrum of the heat flux for $n=920$ spectra on a logarithmic scale and the cospectrum of the heat flux separated into the boundary layer $(n=74)$ and the free troposphere $(n=846)$ on a logarithmic-inear scale.

The absolute value is used in the logarithmic scale to consolidate all spectra on the same plot in order to observe the regimes associated with the buoyancy flux and the Kolmogorov inertial subrange (Hocking 1999; Pope 2000; Stull 2003; Lovejoy et al. 2007). The cospectrum at small scale (inertial subrange) occurs at approximately $\kappa>0.01 \mathrm{~m}^{-1}$, while the cospectrum at large scale (buoyancy range) occurs at approximately $\kappa<0.01 \mathrm{~m}^{-1}$. The integral of the cospectrum over an interval of wavenumbers is equal to the magnitude of heat flux that occurs at the same range of wavenumbers (Stull 2003). Using this principle and inspecting the cospectrum plot, we confirm that large-scale turbulence $\left(\kappa<0.01 \mathrm{~m}^{-1}\right)$, when present, is responsible for the majority of heat flux compared to small-scale turbulence $\left(\kappa>0.01 \mathrm{~m}^{-1}\right)$.

The logarithmic-linear plot shows that the large-scale flux activity is shifted to the positive side from the boundary layer to the free troposphere. This suggests that heat transport is enhanced under countergradient conditions in the free troposphere. [Note that in the mostly stable regime $\left(\frac{\partial \overline{\theta_{v}}}{\partial z}>0\right)$, the positive heat flux is countergradient (Eq. 18)]. 

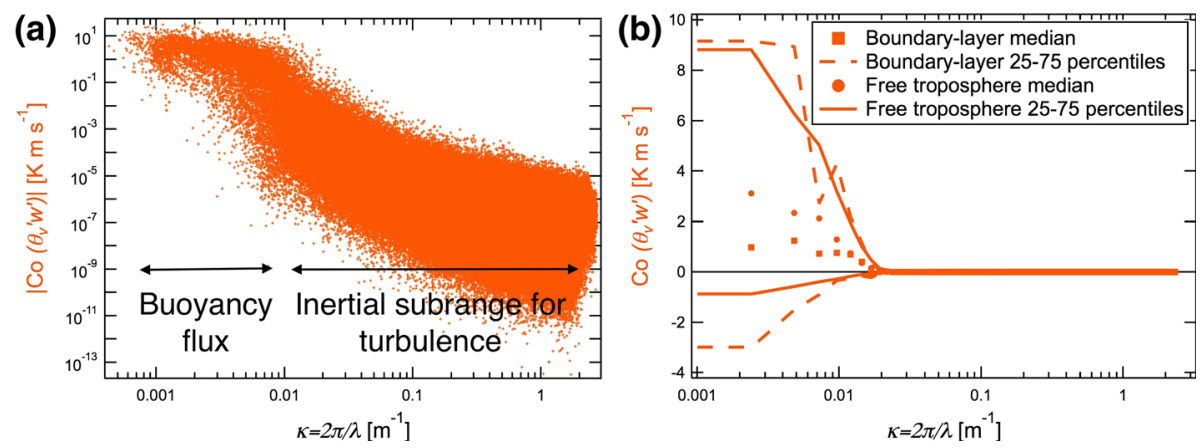

Fig. 10 Absolute value of cospectrum of the heat flux on a logarithmic scale (a) and cospectrum of the heat flux separated in the boundary layer and in the free troposphere on a linear scale $(\mathbf{b})\left(\Delta H=200 \mathrm{~m}, f_{c}=0.025\right.$ $\mathrm{Hz}$ )

\subsection{Experimental Estimation of Terms in the Heat-Flux Budget Equation}

An experimental estimation of the terms involved in the heat-flux budget equation is essential in the understanding of success or failure of suggested parametrizations to formulate heat flux. Our goal is to investigate the significance of each term both in order of magnitude and sign for inclusion in 1.5-order turbulence closure schemes.

Figure 11 shows the measured heat flux and the estimated terms in the heat-flux budget Eq. 16 such as production or consumption by mean potential temperature gradient (XI), transport by turbulent motion (IV), production or consumption by buoyancy (V), pressure redistribution (VIII), and dissipation rate (X) as a function of normalized height or Richardson number. The terms in decreasing order of magnitude are V, IV, XI, VIII, and X. Term VIII exhibits both positive and negative values, and since it was replaced by $-\frac{q}{3 l_{h}} \overline{\theta_{v}^{\prime} w^{\prime}}$ in the derivation of the three parametrizations in Sect. 3, it shows that heat flux exhibits both positive and negative values. Although small, this term cannot be neglected since the heat flux in this term is rearranged to give the parametrizations. Term $\mathrm{X}$ is insignificant and was neglected. Although term IV has similar magnitude as term XI, it was also neglected for simplicity because it contains a third-order moment that requires further parametrization. While term XI is negative, term V is positive. This implies that term XI contributes to the downgradient flux, while term $\mathrm{V}$ is a significant source for the countergradient flux. This budget analysis justifies the inclusion of terms XI and V, i.e. the variances of $w$ and $\theta_{v}$, in the successful parametrization of the countergradient heat flux under statically stable condition, as is considered in Eqs. 18 and 19.

\subsection{The Effect of Cut-off Frequency $\left(f_{c}\right)$ and Height Interval $(\Delta H)$ on Turbulence Measurements}

Measurements of turbulence quantities are sensitive to the choice of cut-off frequency $\left(f_{c}\right)$ and height interval $(\Delta H)$, and a series of sensitivity tests are conducted to investigate the effects. For the sensitivity of turbulence measurements to $f_{c}$, the height interval $\Delta H=$ $200 \mathrm{~m}$ is selected while $f_{c}$ is varied from 0.0125 to $0.2 \mathrm{~Hz}$. This range corresponds to removing fluctuations at length scales from 6.4 to $0.4 \mathrm{~km}$, above and below the average flight length of $5.3 \mathrm{~km}$. Figure 12 shows that with increasing $f_{c}$ the measured turbulence quantities are underestimated while with decreasing $f_{c}$ turbulence quantities reach toward a plateau. 

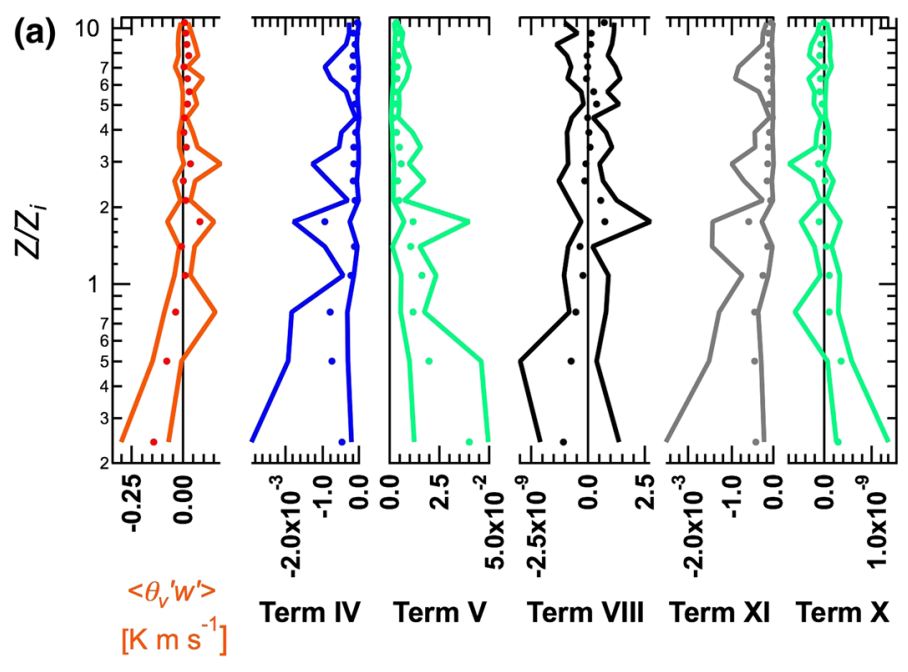

(b)
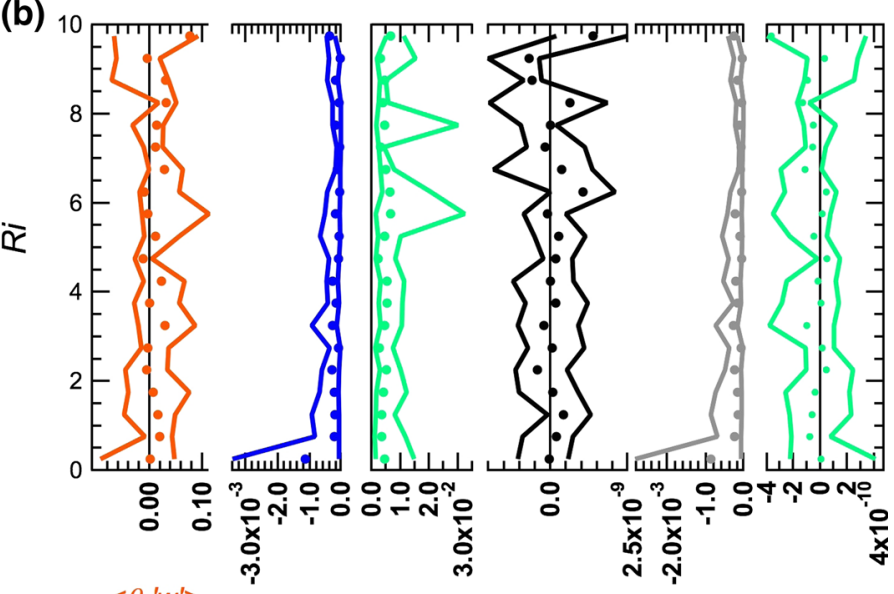

$\left.<\theta_{v}^{\prime} w^{\prime}\right\rangle$

$\left[\mathrm{K} \mathrm{m} \mathrm{s}^{-1}\right]$

Term IV Term V Term VIII Term XI Term X

Fig. 11 Experimental estimates of the terms in the heat-flux budget equation as a function of normalized height (a) and Richardson number (b) $\left(\Delta H=200 \mathrm{~m}, f_{c}=0.025 \mathrm{~Hz}\right)$; on each plot, the left graph is the measured heat flux with a red label, and to the right are the terms in the budget equation that are labelled with black Roman numerals; the lines indicate 25 th and 75 th percentiles and the markers indicate medians

The results associated with $f_{c}=0.0125 \mathrm{~Hz}$ are not shown because this frequency yields identical turbulence quantities to $f_{c}=0.025 \mathrm{~Hz}$.

For the sensitivity of turbulence measurements to height interval, the cut-off frequency of $f_{c}=0.025 \mathrm{~Hz}$ is selected while the height interval is varied from $\Delta H=50 \mathrm{~m}$ to $200 \mathrm{~m}$. At this frequency all SGS fluctuations are contained. Figure 13 shows that with increasing height interval, the measured turbulence quantities increase while with decreasing height interval they are underestimated. This is mainly caused by a significant increase in systematic errors. From modelling considerations, however, turbulence quantities need only be considered and parametrized at the subgrid-scale because larger scales of fluctuations are resolved explicitly. With this consideration, and as is shown in Fig. 13, turbulence fluctuations are a function of grid size (e.g. mixing length) and scale up with increasing grid size. 

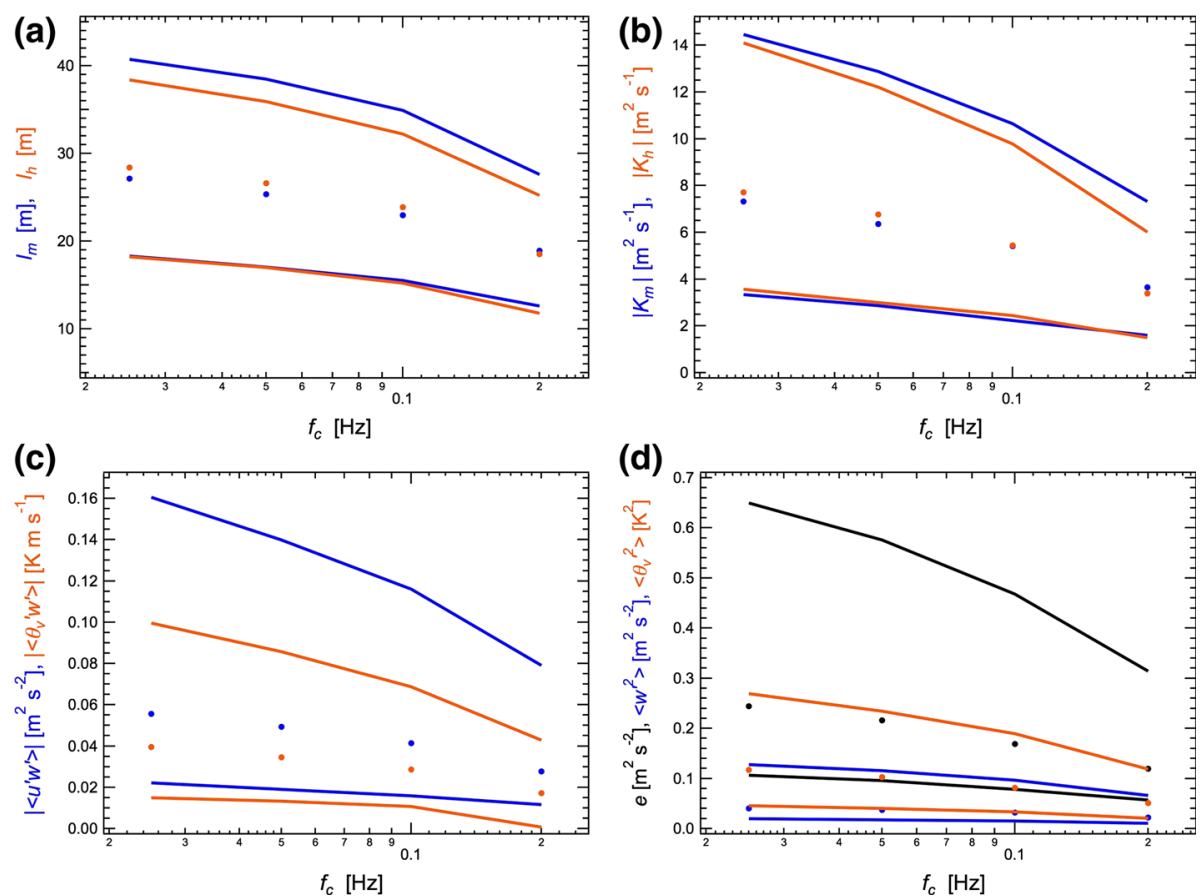

Fig. 12 Sensitivity of turbulence measurements to cut-off frequency for mixing lengths (a), absolute value of momentum and heat diffusivity (b), absolute values of Reynolds stress and heat flux (c), turbulent kinetic energy and variances for vertical velocity and virtual potential temperature fluctuations $(\mathbf{d})(\Delta H=200 \mathrm{~m})$; the lines indicate 25 th and 75 th percentiles and the markers indicate medians

\subsection{Evaluation of Parametrizations for Heat Flux}

The parametrizations in Sect. 3 are evaluated by fitting them against the observed heat flux. The fit is not performed for heat flux averaged over different heights, but rather each measured heat flux associated with a flight leg is compared to the corresponding heat flux estimated by the parametrizations, given the terms that they require, which are also available from the measurements. The fit is performed using genetic optimization. In this technique, a starting guess for the constant(s) to be fitted are provided. Subsequently, multiple iterations are performed to minimize a global cost function, such as the chi squared function calculated for a set of observed versus fitted values, by finding appropriate constants to fit the data efficiently. For details of this technique see Aliabadi et al. (2016a).

Figure 14 shows the comparison as a function of normalized height and Richardson number ( $\Delta H=200 \mathrm{~m}, f_{c}=0.025 \mathrm{~Hz}$ ). The mixing length used for each fit is the median value for the entire dataset already calculated $\left(l_{h}=28.4 \mathrm{~m}\right)$. The fitted constants $C$ for parametrizations 1 and 2 are $0.023 \pm 0.004$ and $0.088 \pm 0.006$, respectively. The biases (parametrized minus observed) for parametrizations 1,2 , and 3 are $-0.049,-0.124$, and $-0.215 \mathrm{~m}$, respectively. The corresponding root-mean-square errors $(R M S E)$ are $0.242,0.372$, and 0.418 , respectively. Due to a large scatter in data, the computed RMSE is 1 to 2 times larger than the 25 th and 75th percentiles for heat flux shown in Fig. 8.

The bias and RMSE values increase from parametrization 1 to 3 no matter the choice of cut-off frequency (not presented), suggesting that parametrization 1 is preferred for two 

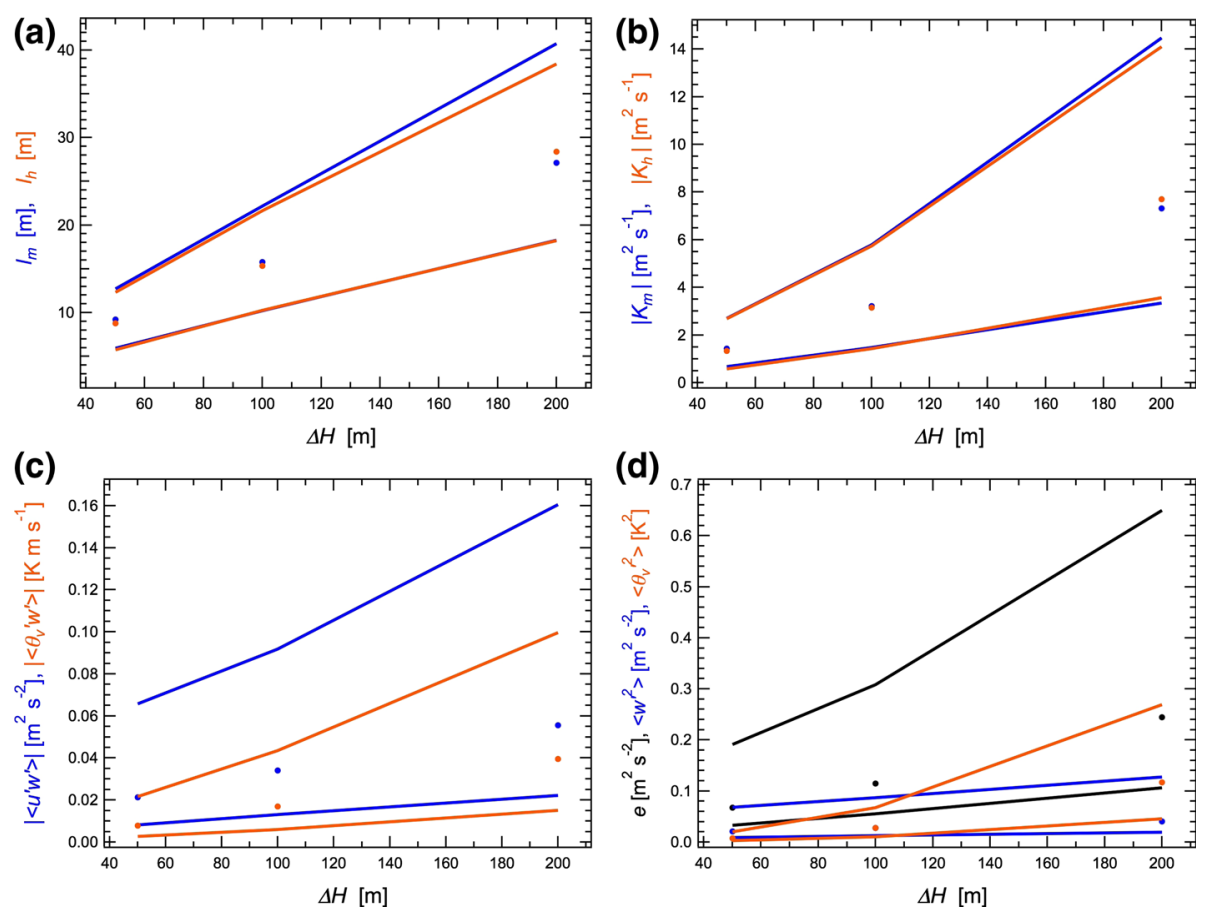

Fig. 13 Sensitivity of turbulence measurements to height interval for mixing lengths (a), absolute value of momentum and heat diffusivity (b), absolute values of Reynolds stress and heat flux (c), turbulent kinetic energy and variances for vertical velocity and virtual potential temperature fluctuations $(\mathbf{d})\left(f_{c}=0.0125 \mathrm{~Hz}\right)$; the lines indicate 25 th and 75 th percentiles and the markers indicate medians

reasons. First, it accounts for the anisotropic nature of turbulence in the troposphere, which is also confirmed by observations of Lovejoy et al. (2007). Second, it incorporates term V in the budget equation to predict the observed countergradient heat transport. The value of the fitted constant $C$ remains practically unchanged for the choice of a cut-off frequency (not presented) as long as only SGS fluctuations are retained. The value of the fitted constant $C$, however, increases by $75 \%$ as we consider the next shorter height interval, i.e. from $\Delta H=200$ to $100 \mathrm{~m}$ or from $\Delta H=100$ to $50 \mathrm{~m}$ (not presented).

\section{Implications of the Heat-Flux Parametrization in Atmospheric Modelling}

An approximate calculation can be performed to investigate the effect of heat-flux parametrization on typical atmospheric model calculations such as that of the mean virtual potential temperature. Assuming no subsidence, horizontal homogeneity, and neglecting radiation, the heat balance Eq. 4 can be simplified to

$$
\frac{\partial \overline{\theta_{v}}}{\partial t}=-\frac{\partial \overline{\theta_{v}^{\prime} w^{\prime}}}{\partial z} .
$$

This equation relates the rate of change of the mean virtual potential temperature to the vertical gradient of heat flux. The change in mean virtual potential temperature during a time 

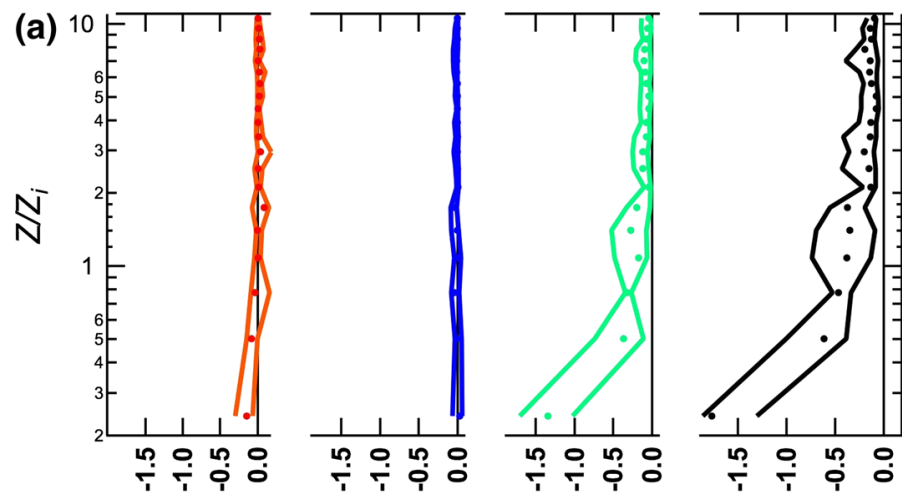

$<\theta_{v}^{\prime} w^{\prime}>$

[K m s $\mathrm{K}^{-1}$ ]

$<\theta_{v}^{\prime} w^{\prime}>$

$<\theta_{v}{ }^{\prime} w^{\prime}>$

[K m s ${ }^{-1}$ ]

[K m s${ }^{-1}$ ]

Param. 1

Param. 2

$\left.<\theta_{v}^{\prime} w^{\prime}\right\rangle$

[K m s${ }^{-1}$ ]

Param. 3
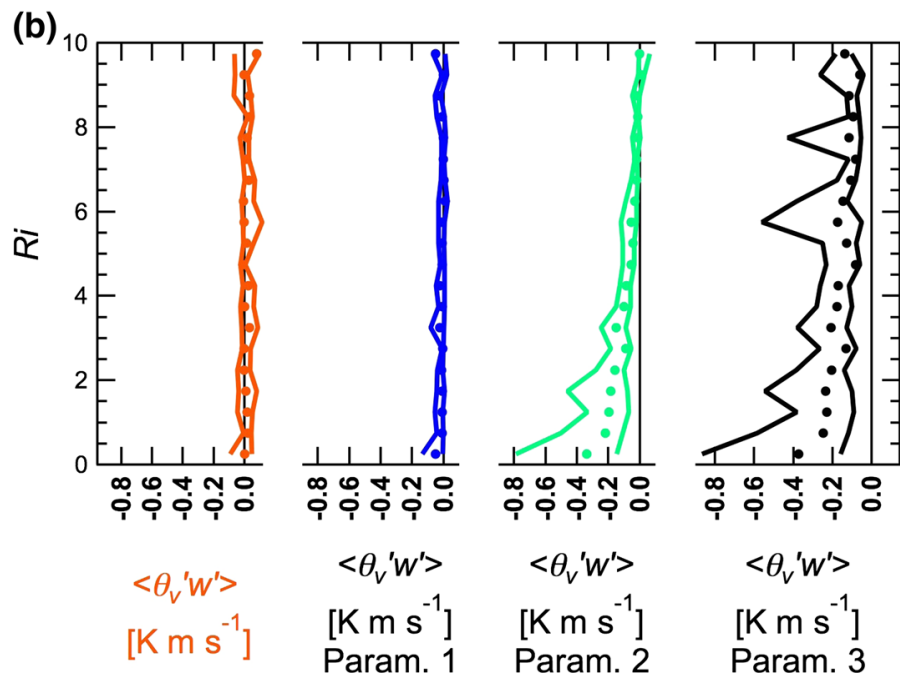

$\left.<\theta_{v}{ }^{\prime} w^{\prime}\right\rangle$

[K m s${ }^{-1}$ ]

Param. 1 $\left.<\theta_{v}{ }^{\prime} w^{\prime}\right\rangle$

[K m s${ }^{-1}$ ]

Param. 2 $\left.<\theta_{v}{ }^{\prime} w^{\prime}\right\rangle$

[K m s${ }^{-1}$ ]

Param. 3

Fig. 14 Comparison between the observed and parametrized heat flux as a function of height (a) and Richardson number $(\mathbf{b})\left(\Delta H=200 \mathrm{~m}, f_{c}=0.025 \mathrm{~Hz}\right)$; the lines indicate 25 th and 75 th percentiles and the markers indicate medians

scale equivalent to the timestep in an atmospheric model $(\Delta t)$ is therefore approximated as $\Delta \overline{\theta_{v}}=-\frac{\partial \overline{\theta_{v}^{\prime} w^{\prime}}}{\partial z} \Delta t$. It is evident from Fig. 14 that the heat flux exhibits a vertical gradient, especially for parametrizations 2 and 3 , so it is expected that this will produce a change in mean virtual potential temperature. We fit a function of the form $\overline{\theta_{v}^{\prime} w^{\prime}}=-a /(1+b z)$ to the median heat flux $\left(\overline{\theta_{v}^{\prime} w^{\prime}}\right)$ and show it in Fig. 15a; the slope of this line at any height is found analytically as

$$
\frac{\partial \overline{\theta_{v}^{\prime} w^{\prime}}}{\partial z}=\frac{a b}{(1+b z)^{2}} .
$$

Therefore the amount of change in mean virtual potential temperature at any height during the model timestep is approximated as 

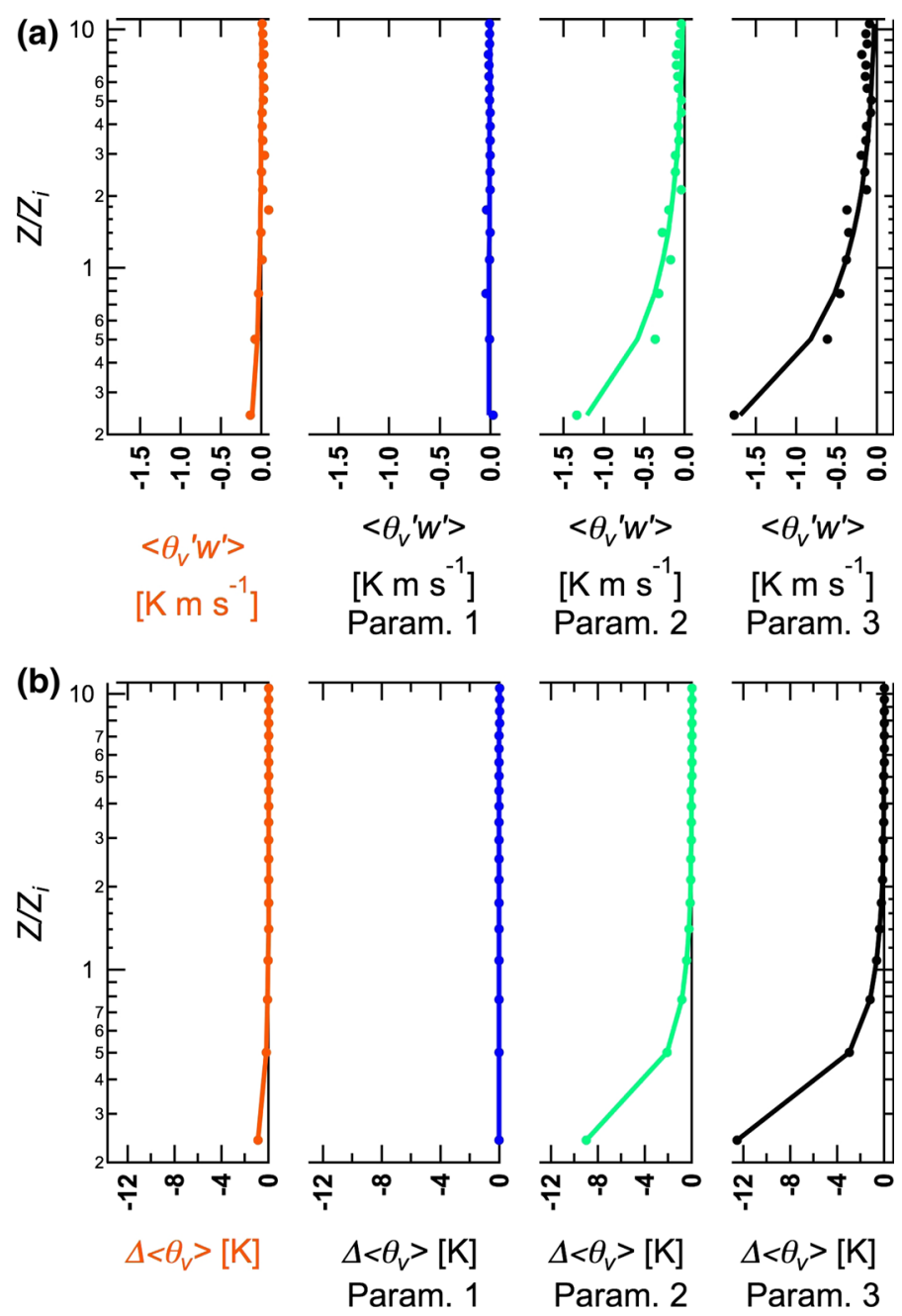

Fig. 15 Median heat flux that is calculated in Fig. 14 (markers) and a smooth fit function of the form $-a /(1+b z)$ (lines) (a) and predicted mean virtual potential temperature change due to heat flux in a time scale typical of a numerical weather prediction timestep $(\Delta t=500 \mathrm{~s})(\mathbf{b})$

$$
\Delta \overline{\theta_{v}}=-\frac{a b}{(1+b z)^{2}} \Delta t
$$

A typical timestep in numerical weather prediction is $\Delta t=500 \mathrm{~s}$, and so a change in mean virtual potential temperature due to heat flux is approximated as shown in Fig. 15b. The predicted temperature change due to heat flux based on the observations during $\Delta t=500$ $\mathrm{s}$ is estimated as $\Delta \overline{\theta_{v}} \approx-1 \mathrm{~K}$ near the lowest level. Parametrization 1 predicts a value of $\Delta \overline{\theta_{v}} \approx-0.01 \mathrm{~K}$, while parametrizations 2 and 3 predict $\Delta \overline{\theta_{v}} \approx-9 \mathrm{~K}$ and $\Delta \overline{\theta_{v}} \approx-12.5 \mathrm{~K}$, respectively. This suggests that atmospheric models utilizing parametrizations 2 and 3 can potentially have a cooling bias due to the heat-flux formulation, particularly at low altitudes within the boundary layer. Of course, we do not present the importance of other terms in the 
Table 3 Parametrization of the inverse turbulent Prandtl number

\begin{tabular}{ll}
\hline Study & $\operatorname{Pr}_{t}^{-1}$ \\
\hline This study & $\frac{0.89}{1+0.01 R i}$ \\
Kondo et al. (1978) & $\frac{1}{7 R i}(1 \leq R i)$ and $\frac{1}{6.873 R i+\frac{1}{1+6.73 R i}}(0 \leq R i \leq 1)$ \\
Kennedy and Shapiro (1980) & $\frac{1}{1+2.1 R i}$ \\
Kim and Mahrt (1992) & $\frac{1}{1.5+3.08 R i}$ \\
Zilitinkevich and Calanca (2000) & $\frac{0.24-0.09 \sqrt{R i}}{R i}(0.28 \leq R i \leq 6.91)$
\end{tabular}

heat balance Eq. 4, such as radiation, but this finding further justifies the use of parametrization 1 to reduce temperature biases due to heat-flux formulation in atmospheric models.

\section{Turbulent Prandtl Number}

Turbulent Prandtl number is calculated for each flight leg using Eq. 7, and an empirical relation is fitted to the data

$$
\operatorname{Pr}_{t}^{-1}=\frac{a}{1+b R i}
$$

The fit is performed using the same genetic optimization discussed in Sect. 4.6; we find $a=0.89 \pm 0.06$ and $b=0.01 \pm 0.02$. The Pearson's chi-squared test for goodness of fit indicates $\chi^{2}=270$ with degrees of freedom $v=n-1=466$. The probability of observing this value of $\chi^{2}$ is $P>0.995$, greater than conventional criteria for statistical significance (0.001-0.005), although we observe a large scatter in the data.

Other formulations in previous studies, which explore the relationship between Richardson number and turbulent Prandtl number, have a similar form and are shown in Table 3 (Kondo et al. 1978; Kennedy and Shapiro 1980; Kim and Mahrt 1992; Zilitinkevich and Calanca 2000). The aircraft study of Kim and Mahrt (1992) was conducted above the boundary layer (2-3 km altitude) for clear-air turbulence measurements over Kansas, Oklahoma, and the Gulf of Mexico. Kennedy and Shapiro (1980) presented a similar study but at altitudes above $7 \mathrm{~km}$ over Kansas, Missouri, Oklahoma and Arkansas. The study by Kondo et al. (1978) was in the Osaki Plain about $35 \mathrm{~km}$ north of Sendai, Japan, using a 22-m tower, and that of Zilitinkevich and Calanca (2000) in West Greenland using a 30-m tower.

While all other formulations suggest that the inverse turbulent Prandtl number should decrease significantly with increasing Richardson number, our results only predict a weak decrease. The large scatter in the turbulent Prandtl number under stable conditions is also observed in other studies [e.g. see Grachev et al. (2007a,b)] due to sampling problems, intermittent nature of turbulence, and other reasons discussed in Sect. 3.

\section{Conclusions and Future Work}

Properties of clear-air turbulence are characterized in the Arctic lower troposphere using aircraft measurements up to a $3 \mathrm{~km}$ altitude. This portion of the atmosphere is dominated by statically stable conditions. There is evidence for both downgradient and countergradient 
vertical transport of momentum and heat, with apparent countergradient transport becoming enhanced above the boundary layer. Three parametrizations are suggested to formulate the heat flux and are evaluated using observations at different flight height intervals $(\Delta H=$ 50, 100, and $200 \mathrm{~m})$ and cut-off frequencies $\left(f_{c}=0.0125,0.025,0.05,0.1\right.$, and 0.2 $\mathrm{Hz})$.

The best-fit parametrization accounts for the anisotropic nature of turbulence (i.e. difference between $\overline{w^{\prime 2}}$ and $\overline{u^{\prime 2}}$ ) and buoyancy flux (i.e. term $\mathrm{V}$ in the heat-flux budget equation) to predict both downgradient and countergradient transport. This parametrization requires modelling of mixing length, turbulent kinetic energy, vertical velocity variance, and virtual potential temperature variance. The parametrization that accounts for only downgradient transport resulted in the largest error, and requires modelling of mixing length and turbulent kinetic energy only. All turbulence quantities and fitted constants are dependent on the choice of flight height interval and cut-off frequency.

Since the parametrizations are fitted for representative vertical resolutions in atmospheric models, they may be used with the suggested constants, however with caution for two reasons. First, larger horizontal sample legs, comparable to horizontal resolution in atmospheric models, would have been necessary in reducing systematic and random errors for turbulence measurements and consequently improvement of the fit for constants. Second, the choice of cut-off frequency would have influences on scales of SGS turbulence that are desired to be resolved, systematic and random errors, and consequently the estimates for turbulence quantities.

Depending on an atmospheric model choice, the turbulent Prandtl number $\left(\mathrm{Pr}_{t}\right)$ may be needed to close a turbulence model scheme. For this purpose we obtain a relationship between $\mathrm{Pr}_{t}^{-1}$ and gradient Richardson number $(\mathrm{Ri})$. There is an indication that the $\mathrm{Pr}_{t}^{-1}$ decreases weakly with increasing $R i$ in a statistically significant way, although with a scatter in the data.

Future work requires characterization of clear-air turbulence under stable conditions at higher altitudes and in other climates using a similar or more accurate methodology. A particular improvement is to increase sampling time so that systematic and random errors in turbulence measurements can be further reduced. It is also desired to cover larger horizontal distances during the sampling time to be more representative of atmospheric model horizontal resolutions $(\approx 10 \mathrm{~km})$.

Although we identify countergradient flux transport processes in the stable Arctic troposphere, we do not have a robust theory for the cause of this phenomenon. Future studies should investigate detailed physical processes that can potentially produce countergradient fluxes in the stable Arctic troposphere (e.g. Kelvin-Helmhottz instabilities, gravity waves, horizontal or vertical advection). We also recommend to run numerical experiments to investigate the effect of including countergradient turbulent flux parametrizations in atmospheric models.

Acknowledgments The authors acknowledge the assistance of M. Wasey (ECCC), A. Elford (ECCC(ECCC)), M. Gehrman (AWI), C. Konrad (AWI), and J. Burkart (University of Toronto) for recovering and processing of the dataset. Expert reviews of the manuscript by J. de Grandpré, S. Bélair, and P. Makar (ECCC) are appreciated. We are grateful for scientific advice from J. Abbatt (University of Toronto) and R. Leaitch (ECCC), from the executive committee of the NETCARE Project. Our greatest appreciation goes to the editors E. Fedorovich and J. R. Garratt and anonymous reviewers of the manuscript who provided detailed comments along with key literature and suggestions to improve the quality of this manuscript. We thank the Nunavut Research Institute and the Nunavut Impact Review Board for licensing the study. Logistical support in Resolute Bay was provided by the Polar Continental Shelf Project (PCSP) of Natural Resources Canada. Funding for this work was provided by the Natural Sciences and Engineering Research Council (NSERC) of Canada under 
A. A. Aliabadi et al.

the CCAR NETCARE project, the Alfred Wegener Institute (AWI), and Environment and Climate Change Canada (ECCC).

\section{Appendix 1: Flight and Radiosonde Schedule for the NETCARE 2014 Campaign}

See Tables 4 and 5 .

Table 4 Flight schedule for the NETCARE 2014 campaign; only research flights listed (5-15); test and ferry flights excluded $(1-4,16-19)$

\begin{tabular}{lllc}
\hline Flight No. & Date & Sampling time interval & Flight duration (h) \\
\hline 5 & 4 July 2014 & $1940-2211$ & 3.7 \\
6 & 5 July 2014 & $1503-1925$ & 4.9 \\
7 & 7 July 2014 & $1506-1941$ & 5.6 \\
8 & 8 July 2014 & $1502-1949$ & 5.3 \\
9 & 10 July 2014 & $1505-1924$ & 5.0 \\
10 & 12 July 2014 & $1828-2256$ & 5.1 \\
11 & 17 July 2014 & $1524-1933$ & 4.7 \\
12 & 19 July 2014 & $1505-1928$ & 5.1 \\
13 & 20 July 2014 & $1501-1917$ & 4.7 \\
14 & 21 July 2014 & $1317-1637$ & 4.0 \\
15 & 21 July 2014 & $1817-2141$ & 4.0 \\
Total & & & 52.1 \\
\hline
\end{tabular}

Table 5 Radiosonde schedule and estimated boundary-layer height $\left(Z_{i}\right)$ for the NETCARE 2014 campaign

\begin{tabular}{lclll}
\hline Platform & No. & Date & Launch time & $Z_{i}(\mathrm{~m})$ \\
\hline Resolute Bay & 1 & 10 July 2014 & 2327 & 131 \\
Resolute Bay & 2 & 11 July 2014 & 2317 & 190 \\
Resolute Bay & 3 & 12 July 2014 & 2315 & 240 \\
Resolute Bay & 4 & 15 July 2014 & 2320 & 301 \\
Resolute Bay & 5 & 16 July 2014 & 2317 & 295 \\
Resolute Bay & 6 & 18 July 2014 & 2317 & 597 \\
Resolute Bay & 7 & 20 July 2014 & 2325 & 384 \\
Resolute Bay & 8 & 21 July 2014 & 2321 & 213 \\
Resolute Bay & 9 & 22 July 2014 & 2319 & 256 \\
Resolute Bay & 10 & 23 July 2014 & 2318 & 563 \\
Amundsen & 11 & 20 July 2014 & 1810 & 387 \\
Amundsen & 12 & 20 July 2014 & 2342 & 49 \\
Amundsen & 13 & 21 July 2014 & 1709 & 177 \\
Amundsen & 14 & 23 July 2014 & 2354 & 67 \\
Mean & & & & $275 \pm 164$ \\
\hline
\end{tabular}




\section{References}

Aliabadi AA, Staebler RM, de Grandpré J, Zadra A, Vaillancourt PA (2016a) Comparison of estimated atmospheric boundary layer mixing height in the Arctic and Southern Great Plains under statically stable conditions: experimental and numerical aspects. Atmos-Ocean 54:60-74

Aliabadi AA, Thomas JL, Herber A, Staebler RM, Leaitch WR, Law KS, Marelle L, Burkart J, Willis M, Abbatt JPD, Bozem H, Hoor P, Köllner F, Schneider J, Levasseur M (2016b) Ship emissions measurement in the Arctic from plume intercepts of the Canadian coast guard Amundsen icebreaker from the Polar 6 aircraft platform. Atmos Chem Phys Discuss 1-37. doi:10.5194/acp-2015-1032

Aliabadi AA, Staebler RM, Sharma S (2015) Air quality monitoring in communities of the Canadian Arctic during the high shipping season with a focus on local and marine pollution. Atmos Chem Phys 15(5):2651-2673

Bélair S, Mailhot J, Strapp JW, MacPherson JI (1999) An examination of local versus nonlocal aspects of a TKE-based boundary layer scheme in clear convective conditions. J Appl Meteorol 38:1499-1518

Bougeault P, Lacarrere P (1989) Parameterization of orography-induced turbulence in a mesobeta-scale model. Mon Weather Rev 117:1872-1890

Cho JYN, Newell RE, Anderson BE, Barrick JDW, Thornhill KL (2003) Characterizations of tropospheric turbulence and stability layers from aircraft observations. J Geophys Res Atmos 108:8784

Cuxart J, Holtslag AAM, Beare RJ, Bazile E, Beljaars A, Cheng A, Conangla L, Ek M, Freedman F, Hamdi R, Kerstein A, Kitagawa H, Lenderink G, Lewellen D, Mailhot J, Mauritsen T, Perov V, Schayes G, Steeneveld G-J, Svensson G, Taylor P, Weng W, Wunsch S, Xu K-M (2006) Single-column model intercomparison for a stably stratified atmospheric boundary layer. Boundary-Layer Meteorol 118:273303

Deardorff JW (1966) The counter-gradient heat flux in the lower atmosphere and in the laboratory. J Atmos Sci 23:503-506

Deardorff JW (1972a) Theoretical expression for the countergradient vertical heat flux. J Geophys Res Atmos 77:5900-5904

Deardorff JW (1972b) Parameterization of the planetary boundary layer for use in general circulation models. Mon Weather Rev 100:93-106

Dehghan A, Hocking WK, Srinivasan R (2014) Comparisons between multiple in-situ aircraft turbulence measurements and radar in the troposphere. J Atmos Sol-Terr Phy 118:64-77

Delage Y (1997) Parameterizing sub-grid scale vertical transport in atmospheric models under statically stable conditions. Boundary-Layer Meteorol 82:23-48

Delage Y, Girard C (1992) Stability functions correct at the free convection limit and consistent for for both the surface and Ekman layers. Boundary-Layer Meteorol 58:19-31

Geernaert GL, Larsen SE, Hansen F (1987) Measurements of the wind stress, heat flux, and turbulence intensity during storm conditions over the North sea. J Geophys Res Oceans 92:13,127-13,139

Grachev AA, Andreas EL, Fairall CW, Guest PS, Persson POG (2007a) On the turbulent Prandtl number in the stable atmospheric boundary layer. Boundary-Layer Meteorol 125:329-341

Grachev AA, Andreas EL, Fairall CW, Guest PS, Persson POG (2007b) SHEBA flux-profile relationships in the stable atmospheric boundary layer. Boundary-Layer Meteorol 124:315-333

Han Z, Zhang M, An J (2009) Sensitivity of air quality model prediction to parameterization of vertical eddy diffusivity. Environ Fluid Mech 9:73-89

Hocking W (1999) The dynamical parameters of turbulence theory as they apply to middle atmosphere studies. Earth Planets Space 51:525-541

Iida O, Nagano Y (2007) Effect of stable-density stratification on counter gradient flux of a homogeneous shear flow. Int J Heat Mass Tran 50:335-347

Inoue J, Kawashima M, Fujiyoshi Y, Wakatsuchi M (2005) Aircraft observations of air-mass modification over the sea of Okhotsk during sea-ice growth. Boundary-Layer Meteorol 117:111-129

Kennedy PJ, Shapiro MA (1980) Further encounters with clear air turbulence in research aircraft. J Atmos Sci 37:986-993

Kim J, Mahrt L (1992) Simple formulation of turbulent mixing in the stable free atmosphere and nocturnal boundary layer. Tellus 44A:381-394

Komori S, Nagata K (1996) Effects of molecular diffusivities on counter-gradient scalar and momentum transfer in strongly stable stratification. J Fluid Mech 326:205-237

Kondo J, Kanechika O, Yasuda N (1978) Heat and momentum transfers under strong stability in the atmospheric surface layer. J Atmos Sci 35:1012-1021

Leaitch WR, Korolev A, Aliabadi AA, Burkart J, Willis M, Abbatt JPD, Bozem H, Hoor P, Köllner F, Schneider J, Herber A, Konrad C, Brauner R (2016) Effects of 20-100 nanometre particles on liquid clouds in the clean summertime Arctic. Atmos Chem Phys Discuss 1-50. doi:10.5194/acp-2015-999 
Lenschow DH, Li XS, Zhu CJ, Stankov BB (1988) The stably stratified boundary layer over the Great Plains. Boundary-Layer Meteorol 42:95-121

Lenschow DH, Mann J, Kristensen L (1994) How long is long enough when measuring fluxes and other turbulence statistics? J Atmos Ocean Technol 11:661-673

Lovejoy S, Tuck AF, Hovde SJ, Schertzer D (2007) Is isotropic turbulence relevant in the atmosphere? Geophys Res Lett 34:L15802

Mahrt L, Vickers D (2003) Formulation of turbulent fluxes in the stable boundary layer. J Atmos Sci 60:25382548

Mahrt L, Vickers D (2005) Boundary-layer adjustment over small-scale changes of surface heat flux. BoundaryLayer Meteorol 116:313-330

Makar PA, Nissen R, Teakles A, Zhang J, Zheng Q, Moran MD, Yau H, diCenzo C (2014) Turbulent transport, emissions and the role of compensating errors in chemical transport models. Geosci Model Dev 7:10011024

Mellor GL (1973) Analytic prediction of the properties of stratified planetary surface layers. J Atmos Sci 30:1061-1069

Mellor GL, Yamada T (1974) A hierarchy of turbulence closure models for planetary boundary layers. J Atmos Sci 31:1791-1806

Ohya Y (2001) Wind-tunnel study of atmospheric stable boundary layers over a rough surface. Boundary-Layer Meteorol 98:57-82

Pope SB (2000) Turbulent flows. Cambridge University Press, Cambridge

Rotta JC (1951) Statistische theorie nichthomogener turbulenz. Z Phys 129:547-572

Stull RB (2003) An introduction to boundary layer meteorology. Kluwer Academic Publishers, Dordrecht

Taylor GI (1938) The spectrum of turbulence. Proc R Soc A164:476-490

Ueda H, Mitsumoto S, Komori S (1981) Buoyancy effects on the turbulent transport processes in the lower atmosphere. Q J R Meteorol Soc 107:561-578

Willis GE, Deardorff JW (1976) On the use of Taylor's translation hypothesis for diffusion in the mixed layer. Q J R Meteorol Soc 102:817-822

Yamada T, Mellor G (1975) A simulation of the Wangara atmospheric boundary layer data. J Atmos Sci 32:2309-2329

Zilitinkevich S, Calanca P (2000) An extended similarity theory for the stably stratified atmospheric surface layer. Q J R Meteorol Soc 126:1913-1923 